\title{
Evolución de las Relaciones Públicas en España. Artículo de revisión
}

\section{Evolution of public relations in Spain. Review article}

\author{
David Caldevilla-Domínguez; Almudena Barrientos-Báez; Javier Fombona-Cadavieco
}

Cómo citar este artículo:

Caldevilla-Domínguez, David; Barrientos-Báez, Almudena; Fombona-Cadavieco, Javier (2020). “Evolución de las Relaciones Públicas en España. Artículo de revisión”. El profesional de la información, v. 29, n. 3, e290305. https://doi.org/10.3145/epi.2020.may.05

Artículo recibido el 10-12-2019 Aceptación definitiva: 12-03-2020

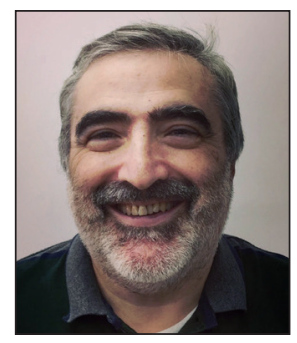

\author{
David Caldevilla-Domínguez $\bowtie$ \\ https://orcid.org/0000-0002-9850-1350 \\ Universidad Complutense \\ Facultad de Ciencias de la Información \\ Av. Complutense, 3. Despacho 510.2 \\ 28024 Madrid, España \\ davidcaldevilla@ccinf.ucm.es
}

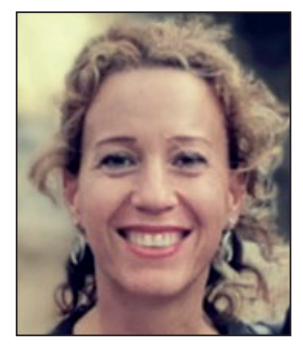

Almudena Barrientos-Báez https://orcid.org/0000-0001-9913-3353

Escuela Universitaria de Turismo Iriarte Paseo Santo Tomás, s/n.

38400 Puerto de la Cruz (Santa Cruz de Tenerife), España

almudenabarrientos@iriarteuniversidad.es

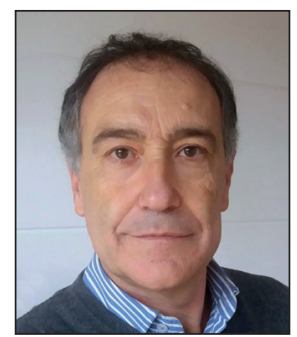

\author{
Javier Fombona-Cadavieco \\ http://orcid.org/0000-0001-5625-5588 \\ Universidad de Oviedo \\ Departamento de Ciencias de la Educación \\ Aniceto Sela, s/n. Despacho 17 \\ 33005 Oviedo (Asturias), España \\ fombona@uniovi.es
}

\section{Resumen}

Se enumeran los hitos cimeros de la historia de las Relaciones Públicas en España con la finalidad de comprender su evolución y actual esencia y definición. Analizamos las técnicas de comunicación persuasivas históricamente empleadas que ya podían tildarse como tales (publicidad, propaganda, protocolo, publicity...) cuando aún no se tenía el concepto actual de Relaciones Públicas. En este artículo se presenta una concepción de Relaciones Públicas basada en su finalidad más persuasiva: la de dirigir la opinión pública. No se olvida la otra gran corriente que se centra en la necesaria generación de simpatía y comprensión entre el emisor y los públicos receptores. Así, las Relaciones Públicas son la unión de diversos elementos que conforman su base conceptual y científica: Mercadotecnia, Prospectiva, Publicidad, Propaganda, Publicity, Patrocinio, Mecenazgo, Comunicación corporativa o Corporate, Comunicación interna, Asuntos públicos, Protocolo y Lobbying o cabildeo. Hay dos grandes influencias en la gestación de las Relaciones Públicas: la Publicidad (Ilamada científica, educativa, social, de prestigio...) y la Propaganda (comercial, colectiva...), por lo que nos centramos en sus padres fundacionales: los profesores y teóricos Pedro Prat Gaballí desde la Publicidad y Francisco García Ruescas desde la Propaganda. Finalmente repasaremos desde los campos del asociacionismo, de la legislación y académico los grandes momentos para el avance de las Relaciones Públicas españolas, pues nuestra finalidad también es crear una cronología lo más completa posible que sirva de base a nuevas investigaciones.

\section{Palabras clave}

Relaciones Públicas; Publicidad; Comunicación persuasiva; Propaganda; Agencias de comunicación; Publicity; Comunicación corporativa; Corporate; Protocolo; Propaganda comercial; Publicidad de prestigio; Publicidad educativa; Publicidad social; Publicidad redaccional; España.

\footnotetext{
Abstract

The first milestones of the history of Public Relations in Spain are listed in order to understand its evolution and current essence and definition. We analyzed the persuasive communication techniques historically used that could already be branded as such (advertising, propaganda, protocol, publicity ...) when the current concept of Public Relations was still lacking. This article presents a conception of Public Relations based on its most persuasive purpose: that of directing
} 
Public Opinion. We do not forget the other great current that focuses on the necessary generation of sympathy and understanding between the issuer and the receiving public. Thus, Public Relations are the union of various elements that make up its conceptual and scientific base: Marketing, Prospective, Advertising, Propaganda, Publicity, Sponsorship, Patronage, Corporate Communication, Internal Communication, Public Affairs, Protocol and Lobbying. There are two great influences in the gestation of Public Relations: Advertising (called scientific, educational, social, prestigious...) and Propaganda (commercial, collective...), so we focus on its founding fathers, the teachers and theorists Pedro Prat Gaballí from Advertising, and Francisco García Ruescas from Propaganda. Finally we will review from the fields of associationism, legislation and academics the great moments for the advancement of Spanish Public Relations, since our purpose is also to create a chronology as complete as possible that serves as the basis for future research.

\section{Keywords}

Public Relations; Advertising; Persuasive communication; Propaganda; Communication Agencies; Publicity; Corporate communication; Corporate; Protocol; History of communication; Commercial propaganda; Prestige advertising; Educational advertising; Social advertising; Editorial advertising; Spain.

"Con una repetición suficiente y la comprensión psicológica de las personas implicadas, no sería imposible probar que, de hecho, un círculo es un cuadrado. Después de todo, ¿qué son un cuadrado y un círculo? Son meras palabras, y las palabras pueden moldearse hasta disfrazar las ideas" (Joseph Goebbels).

\section{Introducción}

Siempre hemos considerado que las Relaciones Públicas son intrínsecas a la interacción entre humanos, sea grupal o individualmente (Caldevilla, 2005a; 2005b; 2007; 2010), biunívoca y de deslocalización de emisor y receptor que opera desde cualquier lugar y en cualquier momento (Fombona-Cadavieco; Goulão; García-Tamargo, 2014) e inherentes al sector del turismo y la inteligencia emocional (Barrientos-Báez, 2019).

Solano-Fleta advertía de la existencia de:

"una corriente que, poco a poco, va abriéndose camino en la conciencia de nuestra sociedad quiere que el ejercicio de las Relaciones Públicas quede circunscrito exclusivamente al ámbito de la comunicación; háblase, incluso, de 'comunicador profesional', soslayando la genuina denominación de Relaciones Públicas para designar ese fenómeno de interacción humana que pretende, por encima de cualesquiera otras finalidades, fortalecer la cohesión social" (Solano-Fleta, 2001, p. 27).

Hasta ahora se ha mostrado como apodíctico que el concepto actual de Relaciones Públicas es consustancial al imperante mercantilismo capitalista, valga el epíteto, derivado de la revolución industrial del siglo XVIII. Los gabinetes de comunicación son parte fundamental en las empresas (De-Urzáiz, 1971; 1977; Grunig, 1992; Solano-Fleta, 1995; Álvarez; Caballero, 1997; Almansa-Martínez, 2004; 2005; Caldevilla, 2005a; 2005b; 2007; 2010; Arceo-Vacas, 2006; Cabrera-Cabrera; Almansa-Martínez, 2011; Armendáriz, 2012; Miquel-Segarra; Navarro-Beltrá, 2016...) pero quizá ésta sea una visión derivada del pragmatismo comercial sajón y, sin ser equivocada, no la entendemos como completa pues, inconcusamente, obvia elementos allende lo pecuniario.

Desde los bajorrelieves que ensalzan a Ramsés II tras la batalla de Qadesh o las tablillas de la versión hitita de dicha batalla que alaban a Muwatalli II, hasta las elecciones consulares en Roma con los clientes de cada gens, pasando por la democracia helena, hallamos mensajes persuasivos, más o menos informativos, con una finalidad clara: atraer al público y moldear su opinión. La mano que mece los medios es la mano que controla el mundo. Es cierto que se trataba de acciones ad hoc, sin rigor científico ni proyección de futuro, aunque con una clara intencionalidad que nos hace pensar en una cierta planificación. Así se mezcla protocolo, propaganda, publicidad, publicity ${ }^{1}$, cabildeo y tantos elementos conformantes y concomitantes con las actuales Relaciones Públicas.

Al margen de usos de los protocolos civil o religioso que son coetáneos a los primeros asentamientos humanos, los principales estudiosos consideran que actos como el Motín del té en 16 de diciembre de 1773 en Boston, aún colonia británica, contra el impuesto de Jorge III (divulgadas inmediatamente por mensajeros a las órdenes de Samuel Adams a fin de provocar un levantamiento) suponen un hito fundacional, dado el inflacionado norteamericano-centrismo que han sufrido siempre las Relaciones Públicas. Recordemos que el motín de Esquilache es de marzo de 1766, en el que algunos enigmáticos personajes estimulaban el descontento en ambientes marginales. Uno era conocido con el nombre de "tío Paco", quien en Lavapiés - un barrio popular del que salió la figura del "Manolo"- pagaba a los chicos por gritar (Andrés-Gallego, 2003).

Para entender la historia de las Relaciones Públicas es nuclear comprender qué son en sí mismas, ontológicamente, ya que esta delimitación conceptual nos permitirá sondear en los adelantados de dichas actividades, incluso antes de que el propio concepto existiera como tal (avant la lettre), aglutinando partes de otros o generando su propio objeto de estudio y desarrollo. 
De entre todos los elementos conformantes de las Relaciones Públicas los más determinantes son la propaganda y la publicidad, ya que los demás conformantes (mercadotécnica, protocolo, cabildeo, comunicación corporativa, publicity, patrocinio...) ocupan un puesto menor dado que su existencia o es posterior en el tiempo, o son elementos más detalladamente focalizados.
En este artículo intentamos superar la tradicional dicotomía entre los que consideran que las Relaciones Públicas en España comienzan en los años 50 y los que consideran que hay una labor previa

\section{Objetivos}

El objetivo del presente artículo es unificar todas las corrientes historicistas de los estudios de las Relaciones Públicas en España, de manera que se superará la tradicional dicotomía entre investigadores que consideran que las Relaciones Públicas en España comienzan en los años 50 con la llegada de las bases militares estadounidenses y la creación de las primeras asociaciones y empresas de Relaciones Públicas así llamadas, y los que consideran que hay una labor de Relaciones Públicas previa al desarrollo de actividades así consideradas. Ambos poseen argumentos en pro y en contra pero definitivamente nuestra cronología de eventos de antes y después del la sustantivación del concepto (año 1957 en pluma de Beneyto) clarificará los postulados. Así estas páginas desean erigirse como un relato cronológico y comentado de las actividades que pueden tildarse como de Relaciones Públicas en España.

\section{Metodología}

Nos basaremos en la técnica exploratoria por antonomasia, la revisión bibliográfica de manera contrastada para cohesionar las fuentes, a veces contradictorias o con lecturas dispares sobre los mismos hechos. Pretendemos no dejar fuera ninguna referencia significativa, aunque por la extensión exigida a este artículo aceptamos que algunos autores se verán menos reflejados de lo merecido.

Afortunadamente existen fuentes primarias, textos redactados por los protagonistas directos de aquellas experiencias, lo que nos ha permitido evitar el sesgo derivado de la exclusividad de trabajos posteriores, o fuentes secundarias, como única versión disponible, aunque por su carácter científico aportan reflexiones muy importantes que han sido analizadas en estas páginas.

Por ello hemos podido focalizar sobre dos corrientes de trabajos de investigación que nos llevarán a considerar como antecedentes cercanos de las Relaciones Públicas de primeros de siglo XX dos áreas emergentes de la comunicación persuasiva: por un lado la Propaganda que nos llevará a considerar a Francisco García Ruescas como uno de los padres de las Relaciones Públicas y por el otro la Publicidad que nos llevará a considerar a Pedro Prat Gaballí como el otro padre fundador desde esta otra área.

\section{Orígenes de las Relaciones Públicas y su concepto}

Reiterando en que el origen de las Relaciones Públicas es inherente al hombre, como ente social, y que se afianzaron con el nacimiento del Estado-Nación, se han desarrollado mucho en los últimos años, bajo el sistema capitalista (Valdez-Zepeda et al., 2018, p. 456).

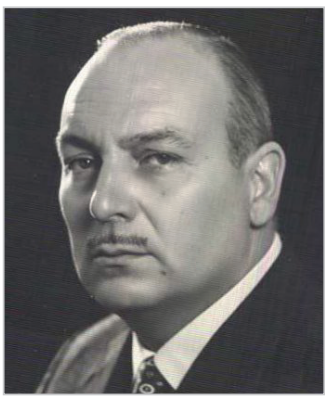

Francisco García Ruescas (1914-2001) https://bit.ly/35st7Dz

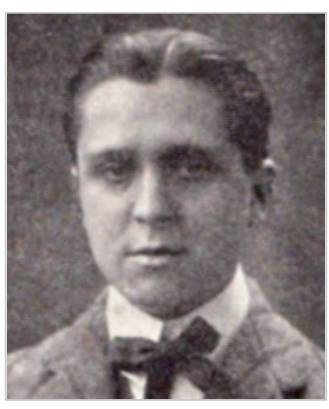

Pedro Prat Gaballí (1885-1962) https://bit.ly/2Wo77p5

El protocolo es quizá la primera de las manifestaciones parciales de las Relaciones Públicas en la Humanidad. Desde las cortes egipcia o babilonia, pasando por las orientales de China o Japón y llegando a nuestros días, sin olvidar los ritos y celebraciones religiosas de todo tiempo, mediante el protocolo de estado y el mercantil o "etiqueta". Con el paso del tiempo

"el concepto de protocolo ha ido evolucionando en los últimos años desde una perspectiva más clásica, entendida bien como el ceremonial y las reglas de ordenación y ciertas pautas de comportamiento o exclusivamente como una técnica al servicio del marketing o de la comunicación -pero auxiliar o secundaria, en todo caso-, hasta el punto de adquirir un planteamiento más complejo, convirtiéndose en eje, en muchas ocasiones, de las estrategias de comunicación diseñadas por empresas o instituciones" (Campos; Fuente, 2013, p. 80).

En España Beneyto (1961) cree hallar Relaciones Públicas en el protocolo y propaganda de las Cortes castellano-leonesas de Alfonso X, con la entrega de regalos de Estado, aunque esa costumbre es consustancial a cualquier corte previa a la del rey Sabio. También podemos citar los concilios católicos hispanos, como el primero celebrado en España, el de Elvira -antiguo nombre de Granada- (hacia el 305) al que asistieron 19 obispos y 26 presbíteros, que ya marcó el discurrir de la Iglesia hispana con sus 81 cánones (mandatos).

Por ejemplo, en Portugal se considera que en la época de los Descubrimientos, el rey Manuel I, considerando de extrema importancia para el buen éxito de los negocios que las compañías comerciales estableciesen exce-
El origen de las Relaciones Públicas es inherente al hombre, como ente social, pero se afianzaron con el nacimiento del Estado-Nación 
lentes relaciones con sus públicos, determinó en 1509

"que sean tratados los mercaderes y personas que tratan en nuestras alcazabas"... "bien oídos, respondidos y despachados (...) y de modo que siempre puedan ir contentos y bien librados de lo suyo y con ruegos y justicia" [traducción propia] (Oliveira-Dos-Santos-Augusto, 2009, p. 119).

Por lo general, y a falta de una más amplia historia europea clarificadora (páginas adelante se citan los principales historiadores en el Manifiesto de Bled), se acepta que el nacimiento de las Relaciones Públicas tiene lugar a principios del siglo XIX en Estados Unidos. Las primeras veces de cuyo uso hay constancia son:

- Thomas Jefferson siendo presidente (1801-1809) de los recién independizados EUA utilizó el término en 1802 (Arceo-Vacas, 1988, pp. 25-27).

- El reverendo Hoyt, quien en 1827 utilizara el término con connotaciones cercanas a la idea de responsabilidad corporativa (Noguero-Grau, 1982; 1985).

- En 1870 se inauguró la primera línea de ferrocarril Nueva York-San Francisco (el transcontinental, o "de costa a costa”). Se considera que es la primera vez que se pretendió sustituir la publicidad de un producto y de una marca por una nueva forma de comunicación: 150 personalidades norteamericanas fueron invitadas (guías de opinión) al viaje inaugural. En uno de los vagones del tren se editó un periódico dirigido a las personalidades que no estaban presentes; de ahí que se entienda que fue una de las primeras acciones conocidas de RRPP antes del propio concepto (Martín-García, 1999).

- El abogado Dorman Eaton en 1882 pronunció una conferencia en la Yale Law School bajo el título "The Public Relations and the duties of the legal profession" (Las Relaciones Públicas y los deberes de la profesión jurídica), con motivo de la entrega de títulos a la promoción de 1882 (Villalba, 2019, pp. 1-2).

A finales del siglo XIX la industria quería organizar la venta de sus productos promocionándolos en prensa y generando aceptación en el público a través del conocimiento de la marca, para lo que se debía crear esa imagen de marca (Prat-Gaballí, 1959, p. 45).

Años más tarde, a principios de siglo XX, la publicidad basada en la muestra del producto no bastaba pues se requería

"una publicidad inspirada en la idea de servicio, de utilidad, de satisfacción de las necesidades o de creación de necesidades nuevas [...]; una publicidad nueva, estudiada a fondo en sus textos y en sus formas gráficas, de modo que pudiese mover los resortes del espíritu humano creando interés y deseo de adquisición" (Prat-Gaballí, 1959, p. 14-15).

Los sectores más adelantados en la búsqueda de una opinión pública favorable fueron: la industria textil, la metalúrgica, la eléctrica, alimentaria, la química y la farmacéutica, en opinión de Prat-Gaballí (1934). En este estado de cosas surgen las Relaciones Públicas "modernas".

\subsection{De la historia al concepto de Relaciones Públicas}

Aunque hoy las Relaciones Públicas presentan una naturaleza bidireccional (lo 2.0 y 3.0 ha calado en lo más profundo de su actividad) debemos retrotraer el calendario a 2007 cuando enunciábamos que nuestro concepto de Relaciones Públicas coincidía con el de Canfield (1962, p. 67)

"el objetivo esencial de las Relaciones Públicas es el de moldear la Opinión Pública e influir sobre ella",

sintonizando así con algunos de los autores clásicos por antonomasia: Lesly (1981), Roggero (1982), o George F. Meredith (ex presidente de la APRA -Association of Public Relations Agencies-, de los EUA) quien afirmó en una entrevista en 1994 que Relaciones Públicas son

“todo lo que entra en juego para lograr una opinión pública favorable" (Caldevilla, 2007, p. 26).

y más actualmente la Indira Gandhi National Open University (Ignou) (2019), quienes sin renunciar al concepto de creación de espacios de mutua comprensión entre público/s y entidad o persona, han visto como parte de su cosmovisión ha sido sepultada por la corriente imperante, ex novo, que aboga por definir la Relaciones Públicas, grosso modo, como un conjunto de actividades que buscan, para una entidad o persona, asegurar el favor, la comprensión y la simpatía del público general o públicos específicos (International Public Relations Association, IPRA2, 1959; I Congreso español de Relaciones Públicas, 1966; Decreto brasileño de Reglamentación de la profesionalización de las Relaciones Públicas, 1968; I Asamblea nacional española de Relaciones Públicas, 1969; Decreto español 1092/75 de 24 de abril, 1975; Federación Interamericana de Asociaciones de Relaciones Públicas (FIARP) 3 , 1978; Public Relations Society of America (PRSA), 1982; Arceo-Vacas, 1988; 2004; 2006; Solano-Fleta, 1995; 1999; Lacasa, 2004; Almansa-Martínez, 2004; Xifra-Triadú, 2006; 2010; Castillo-Esparcia, 2009; Paniagua, 2010; Míguez; Baamonde, 2011; Armendáriz, 2012; Paniagua, 2012; Estanyol; Lalueza, 2014; Reina-Estévez, 2015; Reina-Estévez; González-España, 2014; Miquel-Segarra; Navarro-Beltrá, 2016; IPRA, 2019).

Por su carácter de guía, citaremos la más reciente definición de Relaciones Públicas que la IPRA ofrece, la de 2019:

"Las Relaciones Públicas son una práctica de gestión de toma de decisiones encargada de construir relaciones e intereses entre las organizaciones y sus públicos en función de la entrega de información a través de una ética confiable métodos de comunicación". 
A esta concepción responden Cutlip y Center (1972) y ya en España, Desantes-Guanter (1979), Solano-Fleta (1995) o Caldevilla (2007a; 2007b), al considerar como semántico el problema de las Relaciones Públicas pues engloba conceptos como relaciones, medios empleados y calidad de la institución o persona a partir de sus relaciones. Es perentorio, pues, que las Relaciones Públicas se mueven en el campo grupal (intra e ínter) y persuasivo, concluyendo con Solano-Fleta en que

"desde un punto de vista disciplinar, las Relaciones Públicas serían aquella disciplina que tiene por objeto el estudio de los procesos de interacción organizada modal o procesos de comunicación cuya finalidad directa e inmediata es el mantenimiento del grupo en cuanto tal y tanto en lo que respecta a sus elementos integrantes (procesos de comunicación intragrupales), cuanto en lo que atañe a los restantes grupos que constituyen su entorno social (procesos de comunicación intergrupales)" (Solano-Fleta, 1995, p. 35).

Por ello, queda enmarcada nuestra inicial propuesta y nos reafirmamos en aceptar como irrefutable que la función de las Relaciones Públicas no siempre haya de estar inextricablemente acompañada de una finalidad exclusivamente mercantil, aunque aceptando un amplio componente de la misma.

Estas dos formas de entender las Relaciones Públicas (generar simpatía y moldear la Opinión pública) no son incompatibles, pero llevan aparejadas dos concepciones que nos encauzan hacia los modelos históricos, aunque antes proponemos una imagen ejemplificadora, surgida al socaire del frondoso árbol de la sociología, y más en concreto el de la psicosociología.

Así podremos considerar que las Relaciones Públicas conformarían una casa común, amplia, tecnologizada, psicosociológica y persuasiva que "se vale de" o que "posee habitaciones interconectadas" llamadas Mercadotecnia, Prospectiva, Publicidad, Propaganda, Publicity ${ }^{1}$, Patrocino, Mecenazgo, Comunicación corporativa (o Corporate), Comunica-

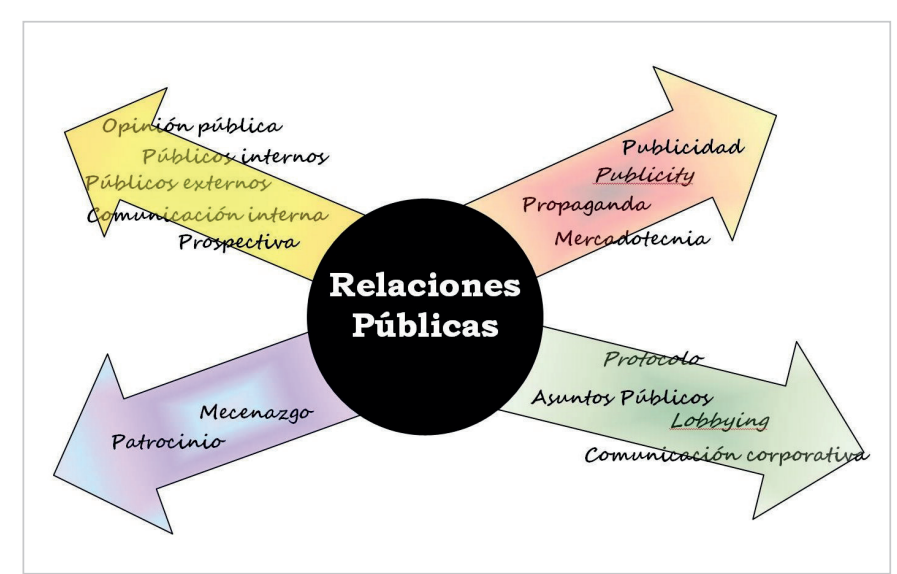

Figura 1. Posicionamiento de las Relaciones Públicas. ción interna, Asuntos públicos, Protocolo y Cabildeo

(o Lobbying). Este cambio de foco, que hace que las Relaciones Públicas iluminen y no sean iluminadas como era habitual en los textos de análisis de sus funciones, es lo que nos permitirá entender mejor cuándo surgen las Relaciones Públicas.

Incluso la tendencia moderna aglutinadora de toda manifestación de la comunicación corporativa, el Corporate, ya bascula hacia aspectos de contenido publirrelacionista a partir de su origen administrativo. Así concordamos con Saladrigas-Medina en que

"la comunicación organizacional (Corporate), vinculada en sus inicios de forma casi exclusiva al campo administrativo es, además, muy joven, tanto que, a pesar de los esfuerzos y desarrollos alcanzados en los últimos cuarenta años, todavía es insuficientemente conocida, e incluso reconocida y su objeto de estudio es, considerado tanto campo propio de las Relaciones Públicas como del Desarrollo Organizacional, de la Psicología Social, de la Sociología, incluso de la Administración o Management" (Saladrigas-Medina, p. 2),

es decir, abarca todas las áreas de la persuasión.

\section{El Corporate, ya bascula hacia aspectos de contenido publirrelacionista a partir de su origen administrativo}

Antes de dar paso a los modelos históricos, queremos resaltar que ya desde 2009 considerábamos que las Relaciones Públicas podían mejorar el futuro porque

"el futuro puede cambiar y ser modificado desde el presente ya que prospectiva significa 'ver hacia delante' y aunque no se puede estudiar el futuro pues éste aún no existe, no es menos cierto que podemos pre-ver (ver con antelación) aquellos futuros que ofrecen más posibilidades de existencia para potenciarlos, erradicarlos o modificarlos según nuestra conciencia ética en cada momento y situación" (Caldevilla, 2009, p. 34).

Esta conformación de un porvenir más acorde a los intereses de un cliente de empresas de Relaciones Públicas es su razón de ser y la prospectiva es su principal herramienta (recuérdese la tercera ley de Dator: "Damos forma a nuestras herramientas y por extensión ellas nos dan forma").

\subsection{Modelos históricos}

Los dos modelos históricamente iniciales serían los agentes de prensa ('husmeadores de basura' incluidos) y el modelo de información pública, asentados ambos en una comunicación lo más veraz y completa posible, con gradientes que van del primero al segundo, y son de naturaleza unidireccional. Arceo-Vacas (2006) considera que estos dos modelos son los que se importan de los EUA con poca o nula adaptación. 
Para este mismo autor, los modelos actuales más en boga, y posteriores cronológicamente a los dos unidireccionales citados, serían el bidireccional asimétrico y el bidireccional simétrico, caldo de cultivo en el que surgen las definiciones más habituales de Relaciones Públicas pues su objetivo no sería persuadir (algo con lo que no podemos estar de acuerdo pues desde sus orígenes la persuasión está en el ADN de las Relaciones Públicas) sino procurar una buena relación entre el emisor y sus públicos.

En palabras de Xifra-Triadú:

"el modelo simétrico bidireccional ha supuesto uno de los ejes vertebradores de teoría contemporánea de las Relaciones Públicas. Constituye el ideal de las Relaciones Públicas, el modelo normativo por excelencia, el que, por ende, ha generado más críticas, revisiones y adaptaciones desde su formulación. Los profesionales de las Relaciones Públicas que lo practican actúan como mediadores entre la organización y los públicos de su entorno. El fin es el entendimiento mutuo entre ambas partes" (Xifra-Triadú, 2008, p. 394).

Finalmente, Arceo-Vacas (2006) aboga por un quinto modelo al que llama 'bidireccional simétrico persuasivo' que hace que el emisor sea líquido (adaptable) al eco recibido de sus públicos a fin de mejorar su persuasión, pues ésta no existe sin una buena relación previa.

Una vez planteado el status quo actual, en el que ya hemos ubicado a las Relaciones Públicas modernas, podremos hablar, caso a caso, del origen de las Relaciones Públicas en España.

\section{Las Relaciones Públicas desde la propaganda y la publicidad}

Muchos investigadores (Almansa-Martínez, 2004; López-Castro, 2005; Rodríguez-Salcedo, 2007; Armendáriz, 2012) consideran que podríamos tomar como alfa fundacional de las Relaciones Públicas al empleo de técnicas de propaganda (llamada en origen propaganda comercial para referirse a la más cercana a las Relaciones Públicas) y de publicidad (Ilamada, a su vez, educacional). Obvio es que en nuestra opinión este extremo es correcto ya que nuestro planteamiento teórico considera a las Relaciones Públicas como una mansión (persuasiva y psicosociológica) formada por varias habitaciones: una de ellas se llama propaganda y otra publicidad.

Armendáriz (2012, p. 25) hila más fino al afirmar que la propaganda que puede entenderse como matriz de las Relaciones Públicas era adjetivada como 'comercial' y la publicidad matricial como 'redaccional' o 'educativa'; Rodríguez-Salcedo (2007, p. 185) tilda a esta publicidad como 'social' o 'de prestigio' al igual que hace Noguero-Grau (1995, p. 140).

En puridad, en España el término Relaciones Públicas se importa desde EUA en los años 50 del siglo XX con la llegada de las bases militares (Solano-Fleta, 1995; Castillo-Esparcia, 2001; Barquero, 2002; Almansa-Martínez, 2004; Xifra-Triadú, 2006; Caldevilla, 2007, Rodríguez-Salcedo, 2007; Armendáriz, 2012...). Sin embargo, en Europa hay estudiosos que consideran que esta visión es simplista ya que en 2002 se confeccionó el "Bled Manifesto on Public Relations" o Manifiesto de Bled para la BledCom 2002 (que fue el 9o Simposio internacional de Investigación en Relaciones Públicas, celebrado en Bled, Eslovenia, organizado por la Asociación Europea de Educación e Investigación en Relaciones Públicas y por la Asociación Europea de Estudiantes de Relaciones Públicas) en el que se reivindicaron las Relaciones Públicas, con remisión a irrefutables datos históricos, como una disciplina que tenía ya asiento en Europa antes de la llegada de los estadounidenses tras la II Guerra Mundial, aunque, eso sí, con otras denominaciones.

El Manifiesto de Bled expone el estatus del conocimiento de las Relaciones Públicas en Europa y alrededor del mundo ya desde su prefacio, que dice lo siguiente:

"La práctica de las Relaciones Públicas en Europa existe desde hace más de un siglo".

Bentele y Szyszka (1995) se refieren a Krups como la primera compañía con un departamento dedicado a las relaciones con la prensa, creada en 1870. L’Etang (1999) sitúa el comienzo de las Relaciones Públicas en Inglaterra en la década de 1920. Lagerwey (1997) muestra que los primeros departamentos de Relaciones Públicas en los Países Bajos también surgieron a principios del siglo XX. Además, los holandeses afirman tener la asociación profesional más antigua del mundo, establecida en 1946 (Denig, 2000). Profesionales y científicos europeos se han reunido a través de la red IPRA durante décadas. Desde 1976 también se han conectado a través de la Confederación Europea de Relaciones Públicas (CERP). A pesar de su larga historia, se sabe poco sobre las Relaciones Públicas en Europa. En toda Europa, los libros de texto estadounidenses se utilizan para estudiar tanto el concepto como la práctica de las Relaciones Públicas. Tales libros ubican el desarrollo de las Relaciones Públicas en los Estados Unidos, y pocos dedican espacio a aspectos de las Relaciones Públicas en otros países.

Es obvio que la enseñanza de las Relaciones Públicas en los países europeos se centra en gran medida en Estados Unidos (Verčič, 2000). Sin embargo, creemos que esto no se aplica a la práctica e investigación del fenómeno. La mayoría de los académicos en Relaciones Públicas creen que éstas son una construcción cultural. Aunque es imposible ver a Europa como un sistema cultural y político único, se puede diferenciar claramente de EUA. Lo que debemos entender es qué es común y qué es diferente de EUA. 
Algunos libros de texto afirman que después de la Segunda Guerra Mundial, las Relaciones Públicas modernas llegaron a Europa, junto con la ayuda de Marshall. Nosotros, y muchos expertos en Relaciones Públicas en Europa, creemos, sin embargo, que las ideas angloamericanas se están mezclando con los conceptos ya existentes de Relaciones Públicas, aunque nunca se los conoce como "Relaciones Públicas" y nunca se estudian como tales. En 1998, comenzamos el debate para responder a la pregunta de si las Relaciones Públicas son sólo un concepto angloamericano o si existe (también) una autenticidad europea de Relaciones Públicas. El estudio Delfos sobre Relaciones Públicas, con participantes de 25 países, es la base de este documento (ver una presentación completa de los resultados en Van-Ruler et al., 2000). Sin embargo, también utilizaremos otras fuentes más informales para tipificar las Relaciones Públicas europeas y plantear algunas preguntas al respecto. Discutiremos cinco temas, planteados por los participantes en el estudio Delfos y discutidos en las tres rondas de este estudio.

Derivado del Manifiesto de Bled anterior afirmamos que aún queda mucho por decir a la hora de paternizar las acciones de Relaciones Públicas en Europa, pero los primeros pilares ya se atisban en este texto. Sea como fuere veremos que en España los referentes serán estadounidenses y derivados mayoritariamente de la Propaganda y de la Publicidad, áreas éstas con fronteras muy difuminadas las más de las veces.

\subsection{Antecedentes en España: propaganda}

Si bien la propaganda (gerundio latino del verbo propagare, que podría traducirse etimológicamente como 'para aumentar los frutos' y que pasó a significar 'lo que ha de ser difundido') surgió en la Iglesia Católica para extender la fe, en especial a los nuevos territorios españoles en América (Sacra Congregatio de Propaganda Fide, creada en 1622 por bula del papa Gregorio XV para ayudar a la evangelización de los misioneros). Los usos posteriores en España se centran más bien en el mundo de la política.

La Propaganda llega al acervo español en la II República, aunque con un precursor en forma de Negociado de prensa, en la época de Primo de Rivera. Pío Baroja (Armendáriz, 2012, p. 21) comenta la existencia de unos "viajes de información" pagados por el Gobierno, de abogados, notarios y registradores que recorrían el país en varios coches Ford para explicar en qué consistía la Reforma agraria de 1932, truncada por la CEDA y posteriormente por la guerra civil.

Si bien es cierto que todos los publirrelacionistas (incluyendo los de primera hora) consideran que no se puede hablar de Relaciones Públicas hasta que llega la democracia, pues lleva aparejada la libertad de expresión, los precursores en España se iniciaron incluso antes del franquismo y durante el mismo.

Oficialmente en noviembre de 1936 la Propaganda entra en el Gobierno: Largo Caballero crea el Ministerio de Propaganda, imitando el caso alemán, bajo el mando desde 1933 (año de subida de Hitler al poder) de Joseph Goebbels ${ }^{4}$, quien ya desde 1930 estuviera al cargo de la propaganda del partido nazi. El designado para dicha cartera fue el periodista alicantino Carlos Esplá Rizo quien la ocupó hasta mayo del 1937, tras la caída de Málaga. Sus labores se incardinan en el momento histórico bélico que pasaba el país, por lo que a su ministerio se deben las campañas de motivación de retaguardia y la famosa cartelería republicana de esa época. Antes de erigirse como ministerio independiente, existía una Sección de Prensa y Propaganda del Ministerio del Estado (hoy del Interior) heredera del Negociado de Prensa del gobierno de Primo de Rivera (Campos-Zabala, 1999).

Armendáriz en su artículo citado (p. 21) alude a una conversación de Esplá con su biógrafo, Angosto-Vélez (2001) en la que comentaba que la "primera campaña de Relaciones Públicas" que él recordaba era la que él atribuía a un paisano suyo de Alicante (Ilamado Federico Soto) que se empeñaba en promocionar su tierra como destino de turismo de invierno, yendo siempre en mangas de camisa para demostrar lo cálido del clima, pese a los catarros que le producía. También se alude a un texto de la novela La llama (1951) de Arturo Barea en el que se menciona la campaña de propaganda [sic] de la empresa de aviación alemana Junkers que envió, en escala de su viaje alrededor del mundo, un cuatrimotor a Madrid en los años 20 del siglo XX en "viaje de propaganda" (p. 591) para atraer a las nuevas compañías aéreas que se formaban entonces y precisaban aviones de gran autonomía. Capítulo aparte merecen los diarios adscritos a pensamientos políticos, sindicales, gremiales o religiosos, muy típicos de los siglos XIX y XX españoles, en especial antes de la guerra civil. Armendáriz (p. 21) cita como ejemplo de prensa corporativa el caso del periódico propagandista (casi 'lobbista') El cortador, del gremio de carniceros y el del mensual El viajero de la Asociación de Hostelería de Barcelona. El siguiente medio impreso, esta vez una revista, dedicado a la propaganda fue Vida española, en 1947, subvencionada por el lobby monárquico español para financiar artículos de viajes por los países monárquicos de Europa y mostrar su bondad social y avances para eliminar la imagen de atraso que el prejuicio español tenía frente a la monarquía (Sentís-Anfruns, 2006).

El turismo quizá fue el sector más adelantado en cuanto al empleo de la propaganda en España, de manera que los trabajos de Cal (1997) muestran cómo ya en el siglo XIX se emplearon técnicas de promoción, privadas o mixtas con las administraciones (a ejemplo de los famosos 'Amigos del país' del XVIII), para promocionar las instalaciones hosteleras del país como fueron las Sociedades de Propaganda del Turismo, implantadas en Barcelona, Madrid y Valencia principalmente. Así, en 1905 se creó el primer órgano oficial en España para la promoción turística, la Comisión Nacional Permanente de Turismo, institución fundamental porque este sector se había visto sometido a innumerables cambios que 
habían modificado el panorama del mercado turístico mundial, como consecuencia del entorno dinámico y competitivo en el que se desarrolla esta actividad (Barrientos-Báez, 2018), hasta que en 1911 toma su relevo la Comisaría Regia de Turismo dependiente de la cartera de Fomento ya que rehabilitaba museos también, para, a su vez ser reemplazada en $1928^{5}$ por el Patronato Nacional de Turismo hasta 1936 cuando estalla la guerra civil y se disuelve, aunque sirve de base para el citado y futuro Ministerio de Propaganda de Largo Caballero. Franco crea en 1938 la Dirección General de Turismo operativa hasta 1973, dependiendo del Ministerio de Información y Turismo desde 1951. Las nuevas competencias autonómicas en 1978 la hicieron cada vez más innecesaria, desapareciendo en 1992. Esta época histórica se encuentra perfectamente documentada en el artículo "La política de comunicación en España durante el franquismo" de Beneyto (1979) en el que repasa el quién es quién de esa amplia época y la estructura estatal a disposición de la propaganda del Régimen.

Se puede afirmar que la propaganda durante el conflicto civil se basó en cartelería en retaguardia para elevar la moral, y canciones en el frente para unir a la tropa. Así

"durante la Guerra Civil se cantaron diversas composiciones con fines propagandísticos, entendiendo como tales aquellas canciones que, por su contenido, forma o trayectoria histórica, política y social están vinculadas a una ideología concreta" (Piñeiro-Otero, 2005, p. 114)

por lo que se puede afirmar que desde 1937 las actividades mercantiles en publicidad o propaganda fueron muy escasas.

Hubo labores personales, tristemente poco estudiadas, dado lo escaso de sus vestigios documentales, como la de Edgar Neville (diplomático español en los años 20 y 30 en EUA -en especial en California- y cineasta afamado) quien en la guerra colaboró con los órganos propagandísticos del gobierno de Franco y ya en los años 50 promocionó, mediante artículos, visitas de escritores y fiestas, lo que él llamaba 'el Malibú español': Marbella. Esta mezcla de periodismo y literatura con la actividad de Relaciones Públicas se puede rastrear a través de la obra de Ríos-Carratalá (citado por Armendáriz, 2012), biógrafo de Neville, quien cita al periodista José Vicente Puente como un adelantado al dirigir las relaciones externas en los años 50 de la Naviera Aznar, flota de cruceros turísticos. Destaca el hecho de que el propio José Vicente Puente ocupase entre 1989 y 1995 un puesto de importancia en el gabinete de prensa de la asociación de navieros españoles.

A finales del 1948 se empezó a editar el Primer Anuario Artístico Publicitario GARÚ en el que se publicaban las campañas publicitarias más exitosas y el listado de agencias de publicidad existentes. En años sucesivos se fueron publicando los siguientes anuarios.

En 1949 hallamos otra de las proto-campañas de unas incipientes Relaciones Públicas en España; citaremos a Rodríguez-Salcedo (2007) quien considera que el Ministerio de Gobernación (hoy llamado de Interior) en dicho año creó una campaña que podría considerarse de Relaciones Públicas ya que a través de la sección de propaganda de la Dirección General de Sanidad mandó publicar una serie de carteles que mostraban consejos y técnicas de mejora de la salud infantil.

En 1949 se funda Ruescas Publicidad como 'Agencia de servicios plenos' entre los que se hallaban los de Relaciones Públicas, aunque sin mencionarlos explícitamente, tal y como reconoce el propio García-Ruescas (1995, p. 102). Una de sus primeras acciones fue editar un boletín mensual para información de sus clientes y que sirviese además de vehículo de promoción de la propia agencia.

En 1951, Ruescas Publicidad comenzó las campañas que Reina-Estévez (2015, p. 60) considera de proto-Relaciones Públicas. Ruescas Publicidad dirigida por Francisco García Ruescas, persona de perfil y currículo impresionantes, donde destacan sus dos diplomaturas por The city of London University, una en 'Dirección de planificación, estrategia y economía de la empresa. Ciencias económicas' y otra en 'Ciencias económicas y marketing' y su título del Ministerio de Información y Turismo con el no 1 de la primera promoción como 'Técnico de publicidad'. Asimismo, fue profesor de publicidad en la Escuela Oficial de Periodismo de Madrid entre los años 1955 y 1964 y director del Instituto Nacional de Publicidad del Ministerio de Información y Turismo (1964-67) además de conferenciante internacional y autor de 13 libros. Fue presidente del Comité Español de Comunicación de la Cámara Internacional de Comercio, presidente de OEC de Marketing, director general de Dardo SA de Publicidad (1941-45), director general de Alas SA de Publicidad (1945-49), presidente y director general de Ruescas Publicidad

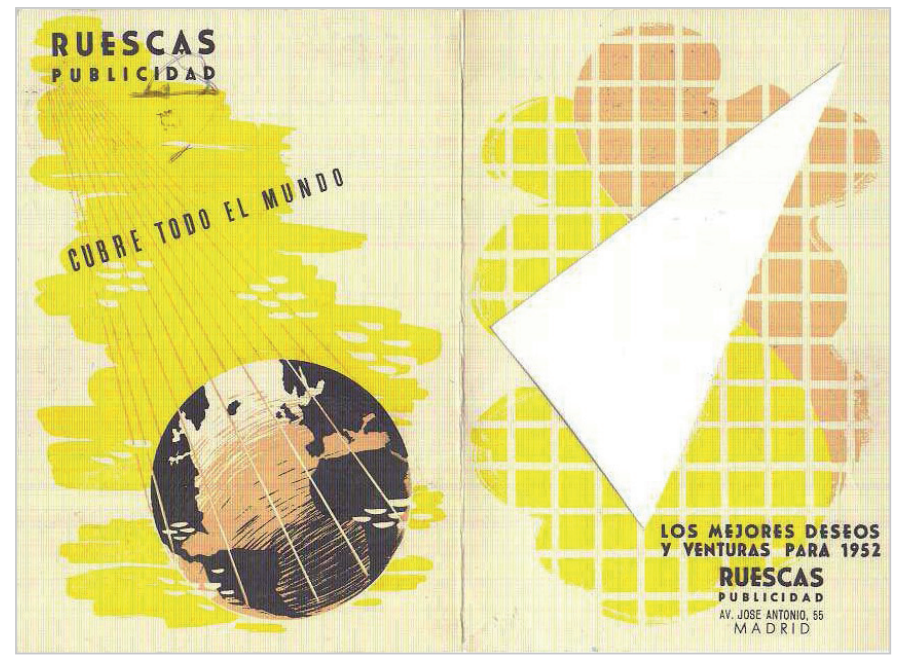

Figura 2. Felicitación de Navidad de 1952 de Ruescas Publicidad. Fuente: Centro de documentación publicitaria.

http://www.lahistoriadelapublicidad.com/protagonista-89/francisco-garciaruescas 
y Marketing y presidente y director general de Ruescas-McCann Erickson SA, miembro del Cenerp y de la Asociación Española de Estudios de Opinión (Ademo). En septiembre de 1961 fue presidente del primer congreso de la International Advertising Association (IAA) celebrado en Madrid. Junto con Prat Gaballí, es uno de los padres de las Relaciones Públicas españolas, también prácticamente desconocido.

En julio de 1953 Ruescas Publicidad se queda con la cuenta de la inauguración del Hotel Castellana-Hilton (14 de julio) hoy Hotel Intercontinental. Francisco García Ruescas dedica dos redactores, un fotógrafo y varios auxiliares para establecer relaciones con los medios de comunicación en una campaña plenamente tildable de Relaciones Públicas pues se gestionó la imagen corporativa, se redactaron comunicados de prensa, se atendió a los periodistas y corresponsales llegados para el fasto y se facilitaron fotos de calidad. Ava Gardner fue una de sus primeras huéspedes, a la que se fueron sumando varias estrellas de Hollywood por lo que la imagen de marca fue siempre acorde a las 5 estrellas que lucía.

En 1954 Ruescas Publicidad gestionó en Madrid una exposición con 200 cuadros canadienses patrocinada por la marca de whisky también canadiense Seagram. La agencia coordinó todas las fases, desde la presentación de la exposición ante los medios en un almuerzo privado -sólo entonces se desveló el nombre del patrocinador- hasta la infraestructura necesaria en la sede de la empresa para el correcto trato de los mensajes e informaciones de entrada y salida, pasando por la selección de las azafatas y su instrucción, así como el envío de mil invitaciones selectivas. Del éxito del evento hablan sus cifras: más de 12.000 visitantes, 920 asistentes de los 1.000 invitados y hasta la presencia de la esposa de Franco, Carmen Polo, quien fuese recibida por el embajador canadiense.

Un caso notorio de Patrocinio que corrobora nuestra teoría de que las Relaciones Públicas abarcan este acto altruista, y no fue el único organizado por Ruescas Publicidad ya que en la misma década de los 50 gestionó patrocinios a concursos hípicos para la marca de cigarrillos Camel, e incluso en 1959 llevó las Relaciones Públicas de la asociación estadounidense World Promotion Pictures en el festival de cine de San Sebastián.

Las Relaciones Públicas españolas llevan el turismo en su ADN: en 1955 se crea el Certamen Nacional de Habaneras de Torrevieja (Alicante) de la mano de Juan Aparicio6, a la sazón Director general de prensa (anteriormente desde 1941 Delegado nacional de prensa y fundador de la Escuela Oficial de Periodismo), con el fin de promocionar el Mediterráneo español en el mundo, a imagen y semejanza del Festival della Canzone Italiana di San Remo, Italia, creado en 1951, al igual que la Mostra Internazionale d'Arte Cinematografica (1932) fuera creada por la propaganda de Mussolini aprovechando la Biennale di Venezia o Francia crease el Festival international du film de Cannes en 1946. En 1959 se crearía el Festival de la canción de Benidorm por el mismo motivo propagandístico y que tantos réditos dio a la música nacional’.

Para Armendáriz, en 1956 principian las Relaciones Públicas con la campaña llamada 'Cruzada de protección ocular' encargada a Juan Viñas Bona ${ }^{8}$, uno de los padres de las Relaciones Públicas profesionales en España como veremos más adelante, y que en la época fue considerada como de propaganda. Su hijo Viñas-Rexach (2003) bucea en los datos de la época y cita el no 51 de 1957 de la revista El óptico profesional. Revista hispanoamericana de óptica en la que se tilda de "propaganda colectiva" y de "campaña de propaganda" al trabajo de Viñas, para pasar en el no 109 de 1963 de dicha revista a ser llamado campaña de Relaciones Públicas.

En su edición no 631 del 1 de enero de 1957 el NODO (Noticiario Documental) se hizo eco de esta campaña con este reportaje:

https://www.rtve.es/alacarta/videos/revistaimagenes/dos-ojos-para-toda-vida-cruzadaproteccion-ocular/2868497

casi un publirreportaje diríamos hoy, en el que se comprueba cuánto de campaña de Relaciones Públicas presentaba esta cruzada frente a

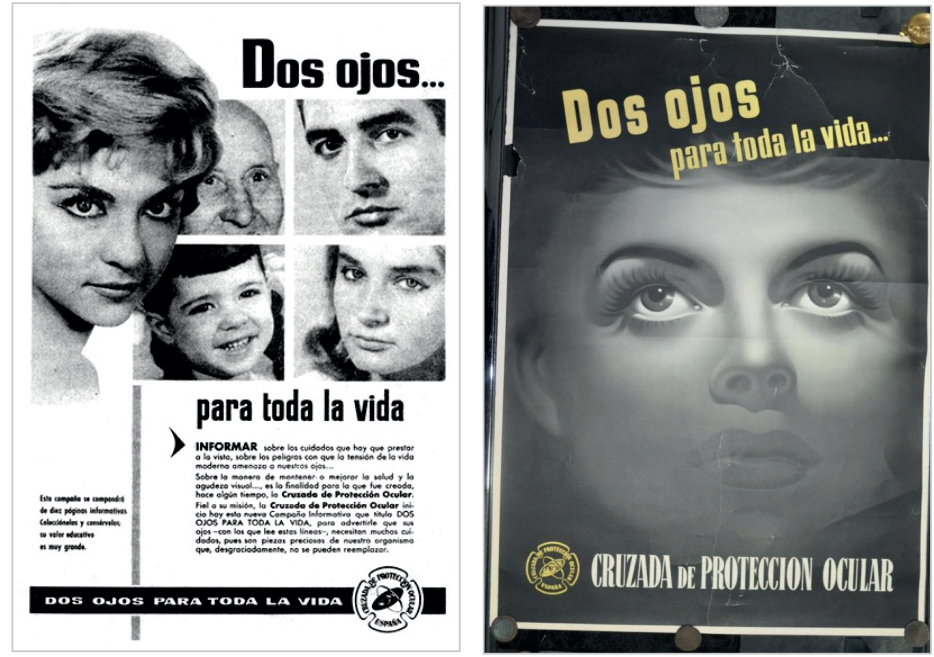

Figura 4. Carteles de la “Cruzada de protección ocular" (1956). Fuente: Todo colección. http://www.todocoleccion.net 
la tradicional publicidad persuasiva mercantil. Pese a lo que pudiese parecer no fue el Estado quien se encargara de fomentar la higiene y el cuidado ocular sino que la campaña fue debida a la compañía INDO, la mayor fabricante de productos de óptica. La campaña, dirigida por Viñas, contó con asistencia puntual de la agencia Danis, y fue tan bien acogida por las autoridades que dio lugar al "Día de la higiene ocular" en la que se recabó el apoyo de oftalmólogos, maestros y medios de comunicación (Rodríguez-Salcedo, 2007, p. 197). Así se desarrolló la operación "Controlvisión" (revisión durante $3 \mathrm{~min}$. de la vista mediante un aparato que detectaba problemas ópticos) que se incluyó en la cartilla escolar como revisión ocular obligatoria. Viñas-Rexach (2003) recuerda que esta "Cruzada de protección ocular" dio origen a un decreto que generó la enseñanza especial para niños con reducida capacidad visual crónica; incluso se crearon concursos de prensa radio y televisión y en última instancia se convocaron congresos, reuniones científicas y semanas de protección ocular por gremios.

El propio Viñas, aún en la década de los 50, firmó una campaña para el Departamento de Comunicación de la Feria de Muestras de Barcelona y el Bazar del Automóvil.

Armendáriz (2012, p. 28) cita una entrevista con Luis Prados de la Plaza en la que éste afirma

"no ha habido un periodista importante desde finales de los 50 hasta el siglo XXI que no haya tenido algo que ver, camuflado o sin camuflar, con las Relaciones Públicas".

\subsection{Antecedentes en España: publicidad}

Separadas las Relaciones Públicas de la Publicidad por muchos autores (Noguero, 1995; Solano-Fleta, 1995; Arceo-Vacas 2004; Almansa-Martínez, 2004; 2005; Xifra-Triadú, 2006; Solano-Santos, 2009; Castillo-Esparcia, 2009; Cabrera-Cabrera; Almansa-Martínez, 2016...) aludiendo al grado de persuasión tanto sea 'sobre' como 'bajo' línea (sean masivas -más publicitarias clásicas- o más particularizadas -más publirrelacionistas-) como al de finalidad: vender productos o servicios en el caso de la publicidad y generar un ambiente de mutua comprensión entre emisor y públicos (potenciales o actuales, internos, externos o ambivalentes) dirigiendo la Opinión pública en el de las Relaciones Públicas, podemos comprobar cómo el origen de las Relaciones Públicas en España se puede hallar también en la deriva de unos usos publicitarios 'atípicos'.

En España se toman como antecedentes lejanos, al margen de los protocolos cortesanos y religiosos citados, actos que podríamos considerar como de Publicity, pues García-Ruescas (1971) clasifica como "gacetilla publicitaria sin señal de pago" a una noticia de carácter comercial que fuera publicada el 1 de octubre de 1792 en el primer número de El diario de Barcelona. Dicha noticia rezaba así:

"Noticia del establecimiento de las pastillas de substancias que de orden de su S.M. se ha hecho en la Provincia de Buenos Aires para el uso de la Marina"

(se trataba de unas pastillas para que los esclavos negros aguantasen mejor la travesía desde África).

La noticia concluía con promesas de producto gratis para los pobres y de donación de parte de las ganancias a fines caritativos, primer caso de mecenazgo publicitado del que se tenga noticia.

El 16 de abril de 1794 en el Diario de Valencia se publicaba otro texto que explicaba que en la botica de Francisco Dolz se vendían polvos de Olivencia para curar enfermedades venéreas.

Conviene recordar (Reina-Estévez; González-España, 2014, p. 6) que la prensa española del siglo XVIII cedía espacios gratuitos a los anunciantes porque consideraban que sus publicaciones eran adquiridas por esas inserciones.

También García-Ruescas (1971) se refiere a la editorial del primer número de la revista femenina La moda elegante, de 1876, para mentar otro caso de proto-Relaciones Públicas al comentar que Ricardo Sepúlveda, el editor, incide en las visitas particulares que mantenía con las suscriptoras, hecho que García-Ruescas tilda de publirrelacionista.

En el mismo 1876, la primera agencia de publicidad de España, la barcelonesa Roldós SA, utilizó una carroza en el desfile del Carnaval de dicho año para promocionar una máquina de coser mediante un artilugio de aire comprimido que lanzaba al aire folletos de dicha máquina que el público se afanaba en coger, logrando según Eguizábal-Maza (1998) que aumentaran considerablemente las ventas.

Hay autores como Rodríguez-Salcedo (2010) que consideran que la empresa suiza Nestlé AEPA es la primera que protagoniza una campaña de Relaciones Públicas al enmascarar un texto publicitario bajo la apariencia de periodístico (publicity) en 1881 en la sección 'Industrias modernas' de la Ilustración española y americana del 22 de diciembre, ya que explicaban cómo elaborar su producto estrella, la harina lacteada, y su importancia en España apoyándose en un dibujo de su fábrica de Vevey (aún quedaban años para su famosa Caja roja). Así, la misma Nestlé en 1888 participó con pabellón propio en la Exposición Universal de Barcelona, lo que se podía interpretar como preparación de su establecimiento en España en 1905.

Para Checa-Godoy (2005) también se observa este tipo de publicity en la prensa gaditana de finales del XIX, reunidos los ejemplos en el Anuario guía de prensa española y empresas conexas, editado en 1897 en Madrid por Francisco Santomé. En él se observan anuncios que se basan en el texto argumentativo con abundancia de datos empleado (al más puro estilo de la llamada Publicidad redaccional). Según Checa-Godoy se buscaba el prestigio y la complicidad del público. 
Así la publicity de la Gran Fábrica de Naipes Finos, sita en Cádiz, se componía de un breve texto que describía parte de la historia y el nivel de producción y distribución de la empresa, que fabricaba cada mes 6.000 barajas y exportaba su famosa baraja andaluza a la República Mexicana y a La Habana; se incluía una ilustración de la fábrica.

El caso de la fábrica de féretros, sarcófagos y arcanas-urnas llamada Nuestra Señora del Pilar es más delicado pues emplea argumentos de corte social, alegando dar trabajo a más de cien obreros según épocas del año. También la labor social es el leit-motiv que encauza la publicity de la Clínica del Doctor Antonio Galván, que anunciaba atender a pobres y acogidos en la Casa Matriz de Expósitos, así como al numeroso personal obrero de la Compañía Trasatlántica (Checa-Godoy, 2005).

En esos años la más original es la malagueña Ceregumil, con gran producción publicitaria, a la que sumó en 1924 promocionales como relojes, plumas estilográficas y lámparas con su logo (Checa-Godoy, 2005).

Llegados a los referentes cercanos, afirmamos que unas de las manos de las que nacieron las Relaciones Públicas en España fueron las de Pedro Prat Gaballí (nacido Prat Jaballí, pero cambió su apellido por cacofónico).

Recurriremos a un libro llamado "La publicidad científica" ${ }^{9}$ para que nos adentre en los primeros años de la publicidad en España. Este texto recoge las clases de enseñanza mercantil que impartiera el adelantado Pedro Prat Gaballí ${ }^{10}$ en el curso 1915-16 en la Cámara de Comercio y Navegación de Barcelona, antigua Casa Lonja del Mar. En su primera edición de 1917 fue editado por la Cámara de Comercio y Navegación de Barcelona bajo el título "Una nueva técnica. La publicidad científica: lecciones explicadas en las clases de enseñanza mercantil de dicha corporación durante el curso 1915-16" por Pedro Prat Gaballí e impreso en la imprenta de Henrich y Compañía, en comandita.

La figura de dicho profesor, el primero de Publicidad en España, es cimera en los albores de este fenómeno persuasivo. Se le considera como el introductor de la publicidad técnica, poniendo los cimientos del oficio con sus innumerables artículos, libros, exposiciones, conferencias y congresos. La Academia de la Publicidad http://www.academiadelapublicidad.org/la-academia

le reconoce el honor de haber sido el primero en la historia en imprimir carácter académico a la publicidad, ya que su citada obra de 1917 "Una nueva técnica. La publicidad científica...", es seis años anterior a la de quien es considerado padre de la profesión, Claude Hopkins y que tenía por título "Scientific advertising".

Tras terminar sus estudios en 1911 en la Escuela de Comercio de Barcelona realiza su primera campaña basada en artículos en diarios y publicidad directa para vender una nueva enciclopedia. En ese mismo año, su relación con Horta quien llegase a ser editor de la efímera revista Comercio, cuyo director fue Prat (primera de publicidad en España 1913-1914), le permite participar en el poemario "Almanach dels noucentistes", alabado por autores como Eugenio D'Ors.

En 1913 dirige la citada Comercio, escribiendo dos artículos cimeros: “La información mercantil en España” (en el no 1 de la revista) y “Enseñanzas de una Exposición Internacional de la Publicidad de Londres” (en el no 3). Un año más tarde crea una sección quincenal llamada 'Técnica de negocios' en El día gráfico. En 1915 Prat publica "La publicidad de nuestro tiempo" (en el tomo II) y "Geografía comercial" (en el tomo IV) de la enciclopedia El comerciante moderno donde también publicó en 1922 el artículo "Técnica de la publicidad”. En el curso 1915-16 imparte la asignatura 'La publicidad científica' en la Cámara de Comercio de Barcelona como parte de las clases de Altos Estudios Comerciales. En el curso 1917-18 en el mismo marco, imparte las clases de 'Ventas por correspondencia y campañas de Navidad'.

Un hecho destaca sobre todos los demás: en 1919 crea y dirige el departamento técnico de la agencia de publicidad Fama (y funda una revista homónima en la que escribe un artículo titulado "El arte de Roberto Cartes" -un dibujante y cartelista- a quien se atribuye el logo de la Agencia Fama, la diosa Fama romana con su trompeta), con la que se inicia lo que autores como Eguizábal-Maza (2002, pp. 65-68; 2003a, pp. 43-64; 2003b, pp. 91-96) dan en Ilamar 'publicidad moderna' en España ya que las agencias hasta entonces eran básicamente distribuidoras de anuncios en la prensa (y más tarde radio). Citemos, siguiendo a Eguizábal-Maza, que en los años 20 desembarcan en España empresas del porte de: Sociedad Petrolífera Shell en Madrid (1920), Nestlé en Barcelona (1920), ITT Compañía Telefónica Nacional de España en Madrid (1923-24), General Eléctrica en Bilbao (1929), Hispano-Olivetti en Barcelona (1929) o Coca-Cola en Madrid (1930).

En 1921 es contratado por la perfumería Casa Gal (activa entre 1898-2004) como representante para Cataluña y Baleares, y entre 1928 y 1935, ya en Madrid, se desempeña como director de Véritas, la agencia que crea derivada del Departamento de Publicidad ${ }^{11}$ donde desarrollaba su labor en dicha perfumería Gal. Su trayectoria profesional en Véritas no puede separase por aquel entonces de la del ilustrador gallego Federico Ribas (1890-1952)

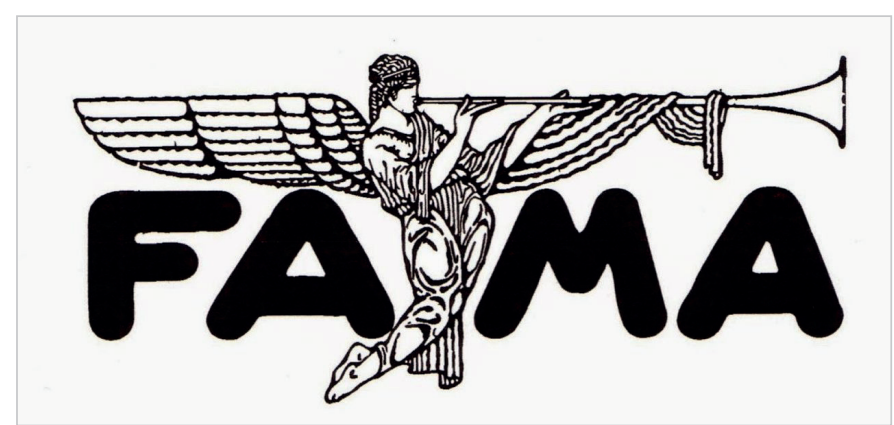

Figura 5. Logotipo de la Agencia Fama atribuido a Roberto Cartes. Fuente: Els meus cartellistes. El blog d'història del cartell de Santi Barjau.

http://cartellistes.blogspot.com/2014/08/la-fama-esquiva-de-robert-cartesper.html 
quien trabajaba ${ }^{12}$ ya para Casa $\mathrm{Gal}$ antes que Prat, cuyos dibujos publicitarios pueden considerarse como los primeros de España, estando influidos por la moda francesa ya que, tras su estancia en Buenos Aires y afincado en París, volvió a España nada más comenzar la I Guerra Mundial. Este tipo de publicidad es propia de Europa y España, donde los textos son mínimos y existe gran apoyo visual, frente a la tradición estadounidense de textos más largos y psicológicos. En el siguiente url podemos ver ejemplos de cartas y carteles de la Agencia Fama gracias a la labor documental de la agencia de publicidad multinacional Grey:

http://www.youtube.com/watch?v=wdG0Tnhly50.

A Prat Gaballí se le atribuye la formación de la Asociación de Profesionales de la Publicidad en 1922 que duró hasta 1928, más tarde y bajo su presidencia la del Publi-Club (1928) que formará parte de la Union continentale de la publicité lo que le permite actuar en diversos foros internacionales y publicar el boletín Opus así como organizar en dicho año de su constitución, la Exposición Bibliográfica de Publicidad y Organización en los salones de la Casa Lonja del Mar (ya nominada como Cámara de Comercio), donde dictase la lección "Los caminos científicos de la publicidad" durante el "Curso de Publicidad y Organización' (las lecciones se editaron en un volumen con el mismo título que el curso). En 1929 se desarrolla el I Congreso Nacional de Publicidad en agosto-septiembre en Barcelona, aprovechando la Exposición Internacional (actas editadas en 1930). Prat defiende la ponencia "Publicidad y mercado" entre otros autores pujantes en el mundo de la publicidad patria. En diciembre de 1930 el /l Congreso Nacional de Publicidad en Madrid (actas publicadas en 1931) es organizado por el Publi-club de Prat, quien pronunciará la conferencia "Posibilidades de la publicidad en el actual momento económico". En diciembre de 1932 publica el artículo "Los albores de una técnica: La publicidad en Cataluña" en Mundo Gráfico. Destaca ese año en la vida de Prat porque se internacionalizan sus aportaciones al asistir al Congreso de Organización Científica del Trabajo en Amsterdam (Holanda) ya que su ponencia "Study of the markets for a popular commodity" (Estudio de los mercados de un producto popular) es editado por la Casa Gal.

En $1933^{13}$ Prat publicó el folleto "Historia documentada de una campaña educativa" sobre su experiencia en la campaña, que Prat Gaballí denominó como "publicidad industrial educadora, de aspecto social" (que ya podemos tildar de Relaciones Públicas) del dentífrico Dens (de la Casa Gal, ya que ésta comenzó a diversificar productos para no estancarse en sus perfumes habituales). Detengámonos en este punto ya que esta conspicua operación es considerada como una campaña publicitaria educativa y no puramente persuasiva (como lo es la publicidad). Así se sirvió de la relación fiducial entre maestro y alumno para llegar a su objetivo que era aumentar el consumo de dentífrico en la infancia. Desde noviembre de 1931 a octubre de 1933 (Rodríguez-Salcedo, 2007, p. 192) la prensa nacional se hizo eco de esta iniciativa (aquí podemos hablar de nuevo de publicity en España antes del término, aunque ningún autor lo ha reflejado así) de manera que se informaba de que se podía hacer la petición de material a Gal para que ésta enviara los artículos de higiene bucal a los colegios así como los pertrechos educativos que el maestro repartía y cuyo uso mostraba. Se logró que en el mundo rural se introdujese este hábito. Este aspecto social lleva a Prat Gaballí a considerar en su libro de 1934, "Publicidad racional", a concretizar, quizá involuntariamente, aspectos publicitarios que flotaban en el ambiente y que sólo esperaban una pluma para ver la luz superando la tradicional lectura económica, alma máter de la publicidad. Así considera que la publicidad debe contribuir

"a todos los intereses colectivos, morales y materiales, a todas las ideología y a todas las grandes acciones nobles" en especial "las acciones sociales que ejerce la generación moderna por medio de la publicidad [...] podemos señalar, entre otras, campañas tan útiles, tan educadoras, tan impregnadas de jugo de civilización como las [...] de nuestros Institutos de Orientación Profesional, contra los accidentes del trabajo; las de nuestras instituciones sanitarias y médicas, contra las moscas, la tuberculosis, el cáncer; la de una compañía de tranvías, contra los accidentes de la circulación; las realizadas a favor de los seguros sociales y algunas que han tenido por objeto el fomento del ahorro" y remata "la publicidad encauza noblemente para mejorar desde algún punto de vista las condiciones sociales [...] la fuerza educadora de la publicidad ha de quedar en lo sucesivo, en el mundo, como una preciada conquista de la civilización" (Prat-Gaballí, 1934, p. 403 y ss.).

Hagamos un breve excurso para entender cómo podía considerarse ya como una campaña colindante con las Relaciones Públicas: en 1921 el prócer Bernays (sobrino de Freud) generó para Procter \& Gamble una campaña nacional en los colegios de EUA en la que se invitaba (bajo promesa de premios para los ganadores) a los niños a realizar esculturas con el Jabón Marfil (inodoro, sin colorantes y 99\% puro) uno de los productos estrella de dicha empresa. Así, los trozos sobrantes o modelos descartados eran regalados a los niños para que lo empleasen en sus casas

"en la cara, manos y baño [...] ya que les encantará la sensación de limpieza que se consigue con un baño de Jabón Marfil una vez al día", 
fomentando de esta forma la higiene. Se calcula que 22 millones de niños participaron, y tras este gran éxito, propuso una carrera de barcos de jabón en el lago del Central Park de Nueva York con bastante aceptación por parte del público. Bernays aplicó aquí una de las enseñanzas básicas de su tío y fundador del psicoanálisis: para que un producto tenga éxito, debe estar en la mente del consumidor, apelando siempre a sus emociones. La gestión de las emociones es un instrumento valioso porque permite la fidelización de clientes al provocar un aumento de la calidad de las experiencias producidas por la maximización de las emociones positivas y la minimización de las negativas (Barrientos-Báez, 2018). Por otro lado, el marketing, la toma de decisiones y la relación con los clientes (Sagarminaga-Gutiérrez; Canals-Parera, 2011) forman un engranaje que se recomienda no romper.

En el caso español, la campaña se basaba en adiestrar al niño para efectuar un cepillado correcto en las aulas, lo que permite a Prat Gaballí (1959) realizar una reflexión sobre otra campaña que le fue encargada en 1911 y que no tilda de "publicidad comercial" ya que, al ser realizada a través de artículos o noticias, la nombra como "publicidad redaccional": que es la que se muestra de manera disimulada para fomentar una asociación de ideas favorables a la empresa, mostrando tres formas:

(1) la de anuncios redaccionales formados por título y un texto pequeño,

(2) la de noticias o comentarios bajo apariencia de asunto de interés general, instructivo, informativo o de entretenimiento, presenta el anuncio comercial al final por sorpresa y

(3) el suelto o artículo de apariencia desinteresada que versa sobre un tema de interés general, en el que no se menciona ninguna empresa, ni producto ni marca ni plantea un objetivo inmediato de utilidad inmediata.

Lo más destacado del libro de 1959 de Prat Gaballí "Publicidad combativa", es que en su página 210 define el concepto de "Relaciones Públicas". Él traduce Public Relations como Relaciones Generales, no Relaciones Públicas (Gutiérrez-García; Rodríguez-Salcedo, 2009; Reina-Estévez; González-España, 2014) por primera vez como

"toda relación simpática que puede ser útil para crear ambiente y fomentar el prestigio de una empresa y de sus productos y marcas".

Montero-Díaz, Rodríguez-Salcedo y Verdera-Albiñana (2010, p. 193) confeccionan una lista de rubros vinculados a las Relaciones Públicas años antes de su denominación como tal: 'relaciones generales', 'publicidad de servicios', 'campañas de propaganda', 'acción social', 'publicidad educativa' y 'publicidad de prestigio', lo que recalca nuestra primitiva idea, plasmada en la figura 1 de este artículo, que defiende que las Relaciones Públicas suponen la casa que engloba habitaciones con esos contenidos.

En 1934 publica su ensalzada obra cumbre "Publicidad racional". En 1935 vuelve a Barcelona tras abandonar Véritas, que queda bajo la dirección de Malcolm Thomson (representante de J. Walter Thomson en España). En 1936 funda en BarceIona una agencia con su propio nombre que es truncada por la guerra civil y académicamente le llega el reconocimiento al crearse para él una cátedra de 'Publicidad y estudios de Mercado' en la Escuela de Altos Estudios Comerciales, pero a la que finalmente no se presenta. En octubre, ya en plena guerra, publica en Mi revista un artículo titulado "La publicidad comercial e industrial". En 1937 en la revista Nova Iberia (editada por la Generalitat de Catalunya) publica el artículo "La enseñanza de la publicidad" como presentación de un curso organizado por el Sindicato de Agentes y Técnicos de Publicidad asociado a la UGT. Prat se encargaría de la asignatura 'Psicología y técnica'.

Acabando la guerra, en 1939 prologa el libro "Economía publicitaria" de J. W. Taylor en el que realiza algunas acotaciones; publica "El poder de la publicidad" y "Nuevos principios de correspondencia comercial". Ese año, finalmente, crea la agencia Oeste (Organizaciones, Estudios y Servicios Técnicos Especializados) aunque en 1947 intenta resucitar con otros publicistas el Publi-club, creando una sección de publicidad dentro del Fomento de las Artes Decorativas (FAD) y en 1950 consigue fundar el Círculo Publicitario -posteriormente transformado en el Club de la Publicidad-cuya lección inaugural imparte bajo el título "Propaganda y opinión pública".

Como buen estudioso y profesor de publicidad, Prat Gaballí recopila anuncios y portadas de revistas de empresa u órganos privados que empiezan su andadura en España en la década de los 40 y recoge en sus textos. Así destaca el Boletín de información, revista mensual editada desde 1947 con 24 páginas de la empresa Firestone-Hispania (instalada en Basauri-Vizcaya- en 1933) o en 1948 la revista Radiografía y fotografías clínicas de la compañía Kodak (instalada en Madrid desde 1913).

Entre 1941 y 1962 -año de su muerte- escribe varios artículos y libros sobre teoría publicitaria (algunos con contenidos de Relaciones Públicas), imparte algunas conferencias y cursos y organiza algunos simposios. Destaca en 1941 su artículo "Necesidad de estadísticas" en el no 10 del Boletín del Sindicato Mercantil y en 1950 su artículo "Cómo fue creada una costumbre" publicado en el no 27 de Arte comercial, dedicado a la publicidad de vinos que sirve a Prat Gaballí para contar la historia de Codorniu, cliente fiel y de primera hora. En 1963, póstumamente, publica un artículo para Publi-club, 
"Historial de nuestro club: primeros pasos" y el prefacio al libro "Thesaurus". Sirvan estos minidocumentales como sentido homenaje a su ingente figura adelantada:

- Pedro Prat Gaballí, miembro de la Academia de Publicidad, por El Publicista (s/f). http://www.youtube.com/watch?v=ockWcXRsQTs

- Prat Gaballí y la revista Fama, de Álvaro; Antona; Arias; Burghiu; Campanero (2016). http://www.youtube.com/watch?v=9NfaWA58rv8

- Homenaje de la agencia J. Walter Thompson http://www.youtube.com/watch?v=K7AYqiGaWMY

- Prat Gaballí, de Molina-Cortés (2015). http://www.youtube.com/watch?v=9S8lgw1kra8

Ya en la década de los 50, una de las siete grandes agencias de España ${ }^{14}$, Publicidad Atlantis, sita en Canarias, organizó para la marca Domecq una serie de eventos públicos y sorteos de vehículos. Los eventos solían consistir en la entrega de los vehículos a los premiados, regalar muestras gratuitas, repartir anuncios impresos y entablar conversaciones con el público directamente.

En 1952 Juan Fontcuberta Vernet creó la agencia de publicidad Danis ${ }^{15}$, ya que éste era el apodo de su socio, Daniel Lladó, quien la abandonó al poco tiempo y cuyo hueco fue ocupado por el hermano de Juan, Francisco Fontcuberta, empleado en Gráficas Manén hasta ese momento. Danis fue la primera empresa en contar con un Departamento de Relaciones Públicas. El propio Fontcuberta en su libro retrospectivo sobre los orígenes de las Relaciones Públicas en España afirma que en Danis pretendieron mejorar la imagen de la labor profesional de la publicidad mediante un plan desarrollado en varias campañas a fin de

"pagar un tributo social para que el público conociese y apreciase el valor de la publicidad" (Fontcuberta-Vernet, 1998, p. 62).

Esta puesta de largo de la publicidad como valor social llevó a considerar a estas campañas como "campañas sociales" o "campañas de prestigio". Destaca la realizada en 1955 y 1956 para un producto ${ }^{16}$ de la empresa gerundense Cadie, formada por 16 anuncios gráficos publicados con periodicidad semanal en la prensa catalana, bajo lemas como 'Un mundo mejor', 'Seamos mejores', 'Sonriamos', '¿Y la cortesía?', ‘No regañemos', 'No discutamos', 'No critiquemos', 'En casa nos esperan', 'Paz en el corazón'... concretamente para su lavavajillas Mistol -de patente francesa- (hoy perteneciente a la multinacional Henkel), primero en venderse embotellado en cristal en 1953 (antes se comercializaban a granel). Otra campaña similar, en 1956, llamada 'Grandes amigos de la Humanidad' fue desarrollada para Rocalla, empresa dedicada a cementos y amiantos para la construcción.

Dados los iniciales éxitos, en Danis comenzaron a contratar personal entre los que se encontraba un viejo amigo, Joaquín Maestre, quien era dueño de una pequeña agencia local en Alicante y que fuese incorporado en julio de 1956, y cuya primera labor consistió en organizar acciones de recuerdo de la campaña 'Seamos mejores' como recuerda en su libro el propio Fontcuberta (1998), aunque hay textos que erróneamente atribuyen a Maestre dicha campaña íntegramente.

En 1956 en una de las múltiples comidas de intelectuales, gente importante de la época, políticos, curas jesuitas..., en la base militar de Torrejón de Ardoz (Madrid) hablando sobre la importancia que estaban cobrando una serie de estudios de Relaciones Públicas en Estados Unidos se gestó la idea de crear una revista sobre Relaciones Públicas en España, cuya dirección sería encargada a Fernando Lozano (Solano-Fleta, 1999).

Para Luis Solano-Fleta, desde 2004 primer catedrático en España de Relaciones Públicas en la Universidad Complutense, la primera campaña de Relaciones Públicas puramente hablando, esta vez sí atribuible al tándem Fontcuberta-Maestre y

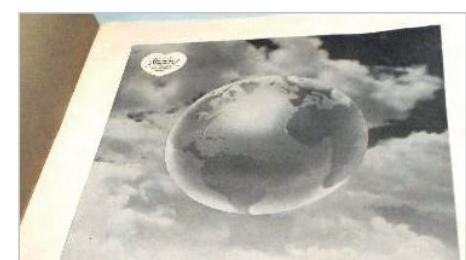

UN MUNDO MEJOR
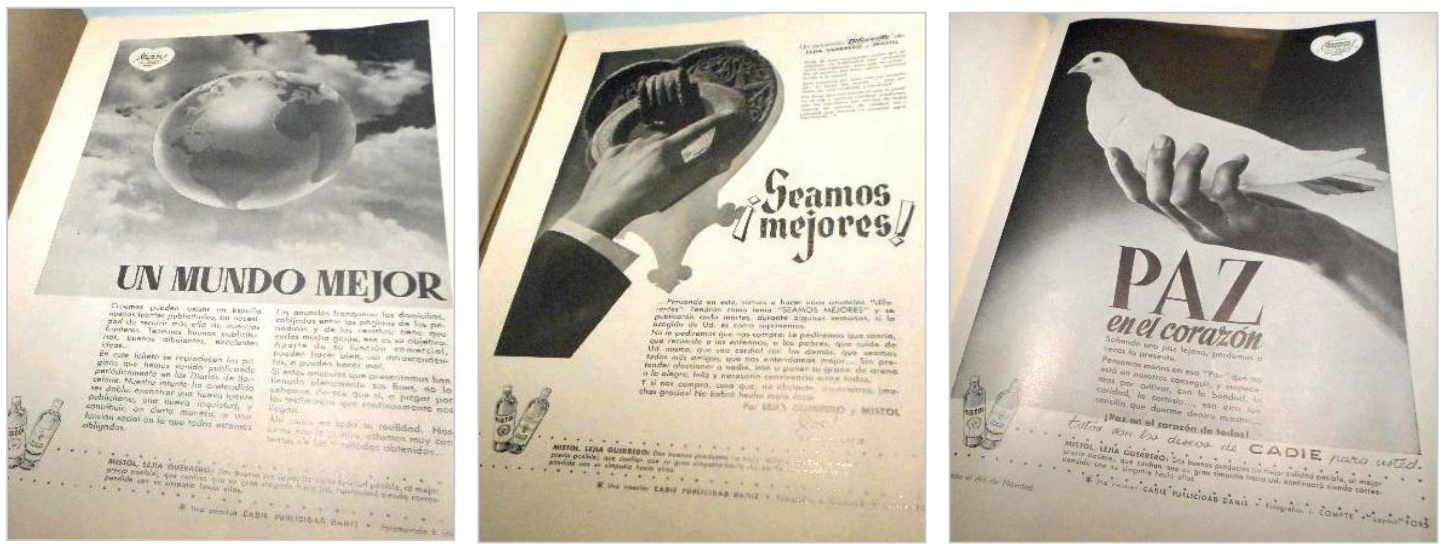

Imagen 7. Imágenes extraídas del catálogo Unos anuncios diferentes de Mistol y Lejía Guerrero de la empresa Cadie. Fuente: Catálogo Unos anuncios diferentes de Mistol y Lejía Guerrero (Agencia de publicidad Danis). 

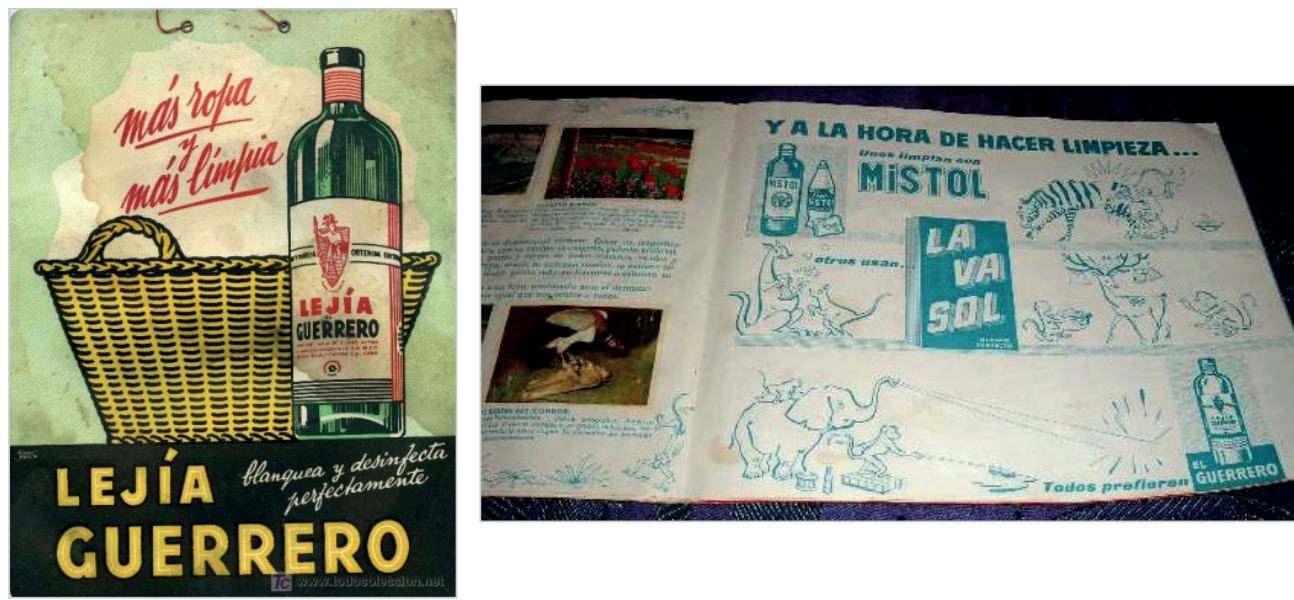

Imágenes 8 y 9. Anuncios de Lejía Guerrero y álbum de cromos de Mistol y Lavasol de la empresa Cadie. Fuente: Blog de Rafael Castillejo. http://www.rafaelcastillejo.com/cosas-3.htm

concebida por Fontcuberta, es la de Transportes Ochoa de Zaragoza (con delegaciones en media España, desapareció en 2013 tras 80 años de actividad), llamada 'Campaña de la Circulación', de 1958 a 1959 -aunque consideramos que abarca hasta 1962 ya que anuncios del mismo tono fueron publicados hasta esa fecha-, en la que se habla de un decálogo de buenas prácticas de conducción para conductores y para peatones. Puso de moda el que los camioneros activaran el intermitente derecho para dar paso a los coches que los deseaban adelantar y pegatinas de respeto al volante colocadas en la parte trasera de los vehículos pesados. Se considera de Relaciones Públicas porque no buscaba ampliar clientela sino mejorar la imagen de los camioneros, que era mala debido a las carreteras tan mediocres que poseía España (sin autovías apenas, atravesando poblaciones, trazados sinuosos, rasantes y desniveles...) que generaban inseguridad pues impedían adelantamientos y limitaban la velocidad de circulación de los coches a la de los lentos camiones de la época. En el desarrollo de esta campaña se conocieron Joaquín Maestre Morata y Juan Viñas Bona.

El concepto 'Campaña de Relaciones Públicas' se atribuye a Juan Beneyto en 1957 ya que en su libro “Mass Communications. Un panorama de los Medios de Información en la Sociedad Moderna" titula uno de sus capítulos "Relaciones Públicas". Este punto iniciático se ve ensombrecido cuando en 1973, en la versión revisada de este texto, que mudó su título por "Conocimiento de la información: aproximación al sistema de las comunicaciones sociales", se elimina toda referencia a Relaciones Públicas aludiendo en el prefacio a que

“la razón de la exclusión de ahora reside en el propósito de centrar las consideraciones en lo que de modo más tópico asoma como información” (Beneyto, 1973, p. 8).

Ya en 1958 se publica "Las Relaciones Públicas en el ámbito local” de Luis Marqués Carbó y Luis G. Marqués Canós, primer libro español sobre Relaciones Públicas en su totalidad (Marqués-Carbó; Marqués-Canós, 1958). Luis Marqués Carbó había ido a estudiar a EUA con una beca y allí descubrió las Relaciones Públicas, importando sus estrategias y tácticas.

En el mismo año, 1958, Maestre conoce en Bruselas accidentalmente a Lucien Matrat ${ }^{17}$, uno de los gurús de las Relaciones Públicas europeas que se hallaba en el Congreso Internacional de la IPRA lo que cambia su visión de las cosas y hace que un neoconverso Maestre comience a utilizar habitualmente el concepto Relaciones Públicas.

\subsection{Las Relaciones Públicas son presentadas en sociedad}

Hay una frase que define perfectamente a lo que deberían dedicarse las empresas "Hacer las cosas bien, y hacerlo saber" tal y como propuso Ivy L. Lee en sus comienzos.

Un hito fundamental para las Relaciones Públicas en España acaece en 1953. Ese año la España de Franco firmó con los EUA de Eisenhower (el famoso Ike) el acuerdo que sacaría a España de su autarquía y aislamiento, llamado Pactos de Madrid, y entre ellos el Acuerdo de colaboración y defensa mutua, también conocido como "Rendición de Torrejón" por el que España cedía 9 bases a la completa, excluyente y total soberanía extranjera de los Estados Unidos ${ }^{18}$ a cambio de unas ridículas contraprestaciones económicas y militares ${ }^{19}$ pero de gran resonancia política al ser la España de Franco admitida en los principales centros políticos del mundo. Al final,

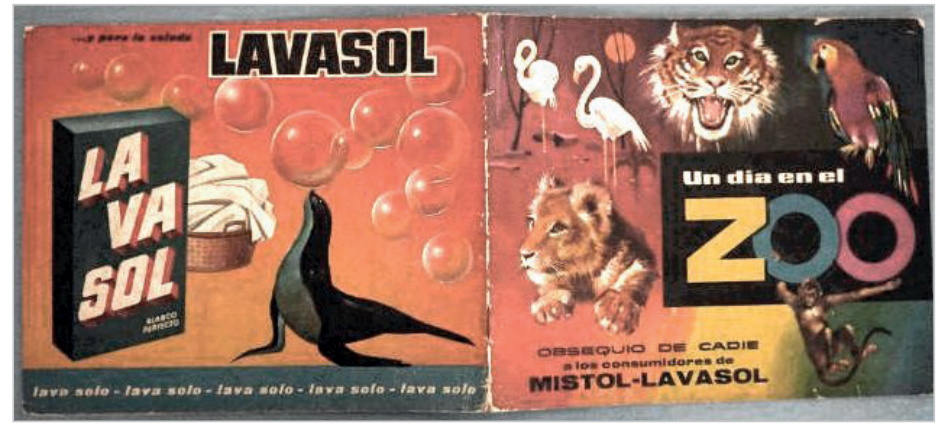

Imagen 10. Álbum de cromos de Mistol y Lavasol de la empresa Cadie. Fuente: Blog de Rafael Castillejo.

http://www.rafaelcastillejo.com/cosas-3.htm 
de 9 se pasó a sólo 4 ya que no eran necesarios más establecimientos militares según el Pentágono. Este acuerdo fue "ratificado" en 1987, ya en democracia, mediante el llamado 'Referéndum de permanencia en la OTAN', que supuso una verdadera campaña de publicidad y Relaciones Públicas para el gobierno del PSOE (uno de cuyos lemas asamblearios había sido "OTAN, de entrada no") a fin de mudar la mayoritariamente tendencia inicial al voto negativo (incluso el principal partido de derechas, Alianza Popular dirigida por el exministro de Información y Turismo franquista, Manuel Fraga, -quien popularizase el previo «España es diferente»-, optó por apoyar la abstención) por el sí a la OTAN. Siempre planeó la sombra del pucherazo en los resultados (Caldevilla, 2007, p. 204).

En noviembre de 1960 se crea en Barcelona (años más tarde, en 1974, abriría delegación en Madrid) la primera agencia de Relaciones Públicas en España propiamente nombrada, la Sociedad Anónima Española de Relaciones Públicas, más conocida como SAE de Relaciones Públicas (absorbida en los años noventa por la actual Weber Shandwick Ibérica) a cuyo frente se hallaban los citados Joaquín Maestre -director hasta 2002- (quien fundase en 1991 la Asociación de Empresas Consultoras en Relaciones Públicas y Comunicación, Adecec) y Juan Viñas. http://www.adecec.com

Se puede decir por ello que de una escisión de Danis surgió la que sería la primera agencia de Relaciones Públicas de España. Al principio dedicada a organizar eventos como el / Certamen español de moda masculina de 1960 para su primer cliente, el Consejo Español de Sastres o los 50 años de Almacenes Jorba (Barcelona) en 1961 o en 1962 la puesta en marcha del salón gastronómico Hogarotel y en 1963 citaremos, finalmente, el Festival de la infancia, entre muchos más (Rodríguez-Salcedo, 2010).

Rafael Ansón Oliart, una personalidad de la comunicación de esa época, en otra de las citadas comidas en la base de Torrejón de Ardoz, llevó una serie de estatutos sobre Relaciones Públicas y así se empezó a institucionalizar: el 8 de marzo de 1961 se crea en Madrid la Asociación Técnica de Relaciones Públicas (ATPR) formado por aquellos profesionales que se reunían en la base con lo que el nacimiento de las Relaciones Públicas se asocia indefectiblemente a la presencia de bases militares estadounidenses en España, lugar de cita de los citados intelectuales, empresarios y personalidades de aquellos años. Dichos representantes participaron en el II Congreso Internacional de la International Public Relations Association (IPRA).

Volviendo a SAE de Relaciones Públicas, los trabajos de análisis publirrelacionísticos centrados en su historia suelen converger en considerar tres etapas en el discurrir mercantil de la empresa en paralelo con la evolución del país: (a) 1960-63 en la que la empresa inicia su singladura, (b) 1964-67 coincidiendo con el I plan de desarrollo franquista y (c) 1968-75 mientras se desarrollaron el II y III plan de desarrollo.

En cada etapa, sus principales clientes se pueden encuadrar en gremios:

(a) muchas industrias textiles (Rodríguez-Salcedo, 2007, p. 199): el primer cliente fue el Consejo Español de Sastres en 1960, los Fabricantes de Pañería Confederados (1960-61), Textomatic'75 (1961), Instituto Coordinador de la Moda Española (1961), Rexor (1961), Acrilán (1961), el Department of Agriculture de los Estados Unidos (USDA) (1963) y el británico International Wool Secretariat (IWS) (1963);

(b) en esta segunda etapa la clientela aumenta proveniente del sector hidroeléctrico y turístico, entre los que destacan empresas como: Laboratorios Hubber (1964), Mitsui y Toshiba (1964), Henkel Ibérica (1964), Department of Trade and Commerce de Canadá (1966), Banco Fuji (1966), Hong Kong Trade Development Council (1966), BASF (1968), John Deere (1968) y la compañía tabaquera Reynolds (1968). En casi todos estos casos se trataba de preparación de ferias, inauguraciones, misiones comerciales o promociones;

(c) finalmente, en esta última etapa se consiguen clientes impensables con anterioridad: las Administraciones Públicas y la Iglesia así como el sector turístico aunque los principales ingresos derivaron de la organización de eventos como premios literarios, convenciones, promociones, asistencia a salones y organización de concursos para clientes ya existentes como Editorial Matau (desde 1961), Editorial Planeta con su famoso premio (desde 1961), Patronato de apuestas deportivas (desde 1961), Ford (1961), Secretariado de Suburbios del Obispado de Madrid-Alcalá (desde 1961), Amigos de Coches Veteranos (desde 1962), Coca-Cola (desde 1962), Miss Naciones Unidas (desde 1963) y el Club de Golf de San Cugat (desde 1964). Durante esta tercera época, SAE de Relaciones Públicas amplió su espectro mercantil ofertando 
“Consejeros de dirección en técnicas de comunicación social y públicas, análisis de opinión e imagen. Estudios psico-sociológicos para la empresa, programas promocionales e información industrial y socioeconómica”.

En 1961 Juan Aparicio se convirtió en el primer presidente de la Asociación Técnica de Relaciones Públicas, órgano adelantado pero efímero, pues duró dos años, del publirrelacionismo español y cuya misión según López-Castro (2007, p. 519) era

"aunar a todos los especialistas de esta disciplina para defender sus intereses y divulgar la profesión".

Tan importante es el turismo para España que se puede considerar que, tras el fratricida conflicto bélico, y al margen de una pequeña publicidad mercantil tintada por la guerra ('Los rojos no llevaban sombrero' rezaba un lema de una sombrerería de la época), sólo las campañas institucionales de promoción del turismo vacacional se erigen como la única propaganda activa. Técnicos españoles, a fin de atraer turistas, comienzan a efectuar lo que Armendáriz ( $p$. 24) llama excursiones de propaganda. Armendáriz, citando a Correyero-Ruiz (2003) destaca la gira del entonces Director General de Turismo, Luis Antonio Bolín, de dos meses por Europa y Estados Unidos, donde inaugura oficinas de turismo en Nueva York, Chicago, Los Ángeles y San Francisco. Surge el ya mítico «España es preciosa y diferente, visite España», lema patrio por antonomasia y predecesor de la Marca España actual. Su labor consistía según Armendáriz, quien cita a Correyero-Ruiz (2003, p. 55), en celebrar reuniones y banquetes con los guías de opinión y prescriptores más notables (periodistas, representantes sociales, españoles emigrantes...) así como con expertos del sector turístico (agentes de viajes) a los que se les proyectaba una película sobre España y se les ofrendaba con bailes y viandas típicas (hoy conocidos como fam trip pero visitando el destino).

En cuanto al caso de los diarios, por lo prolijo de su enumeración e historia, baste decir que el empleo de la propaganda tuvo en ellos ejemplos más que significativos; y ya durante la guerra civil el caso de los dos $A B C$, el sevillano profranquista y el madrileño progubernamental, sirve para ejemplificar cómo la prensa fue empleada en este tipo de tácticas, amén del uso de Radio Sevilla por parte del general sublevado Queipo de Llano o en la postguerra Radio España Independiente (popularmente conocida como Radio Pirenaica) gestionada por el Partido Comunista de España en el exilio, que emitió de 1941 a 1977, primero desde la URSS y a partir de 1955 desde Rumanía.

En 1964, el Instituto de Técnicas para la Comunicación Social de Barcelona comienza su primer curso sobre Relaciones Públicas.

En 1965 se funda "Ulled y Asociados, consejeros de Relaciones Públicas" a cuya cabeza se hallaba Jesús Ulled, otra de las figuras cimeras nacionales pero entre ambas se cuelan las creaciones de los primeros departamentos de Relaciones Públicas en instituciones oficiales y en empresas de gran calado como Renfe ${ }^{20}$ (1963), Ayuntamiento de Santiago de Compostela y Ayuntamiento de La Coruña (1964) -ambos ayuntamientos crearon sendos departamentos de Relaciones Públicas-, el IN/21 (1965), Empresa Nacional Calvo Sotelo-hidrocarburos-, Movie Record-publicidad en cines- o McCann Erickson -agencia de publicidad- (1966).

En 1965, tras el cese de la actividad de la ATRP, prácticamente sus mismos miembros el 26 de agosto de 1965 llevan a cabo el acto de presentación de la Agrupación de Relaciones Públicas en Barcelona, que aparece casi a la vez que el Centro Español de Relaciones Públicas (Cenerp) de Madrid, a las que se suma en 1968 el Centro Mallorquín de Relaciones Públicas (Cemarp).

Por otra parte Rico Zorrilla, director del Instituto Nacional de Industria (INI) que fundamentalmente apoyaba al textil español en Barcelona -una de las razones por las que las Relaciones Públicas nacieran allí- en cierto modo obliga a las empresas a fomentar esta disciplina estableciendo que cada empresa del INI debería tener un director, responsable de un departamento de Relaciones Públicas (Caldevilla, 2007).
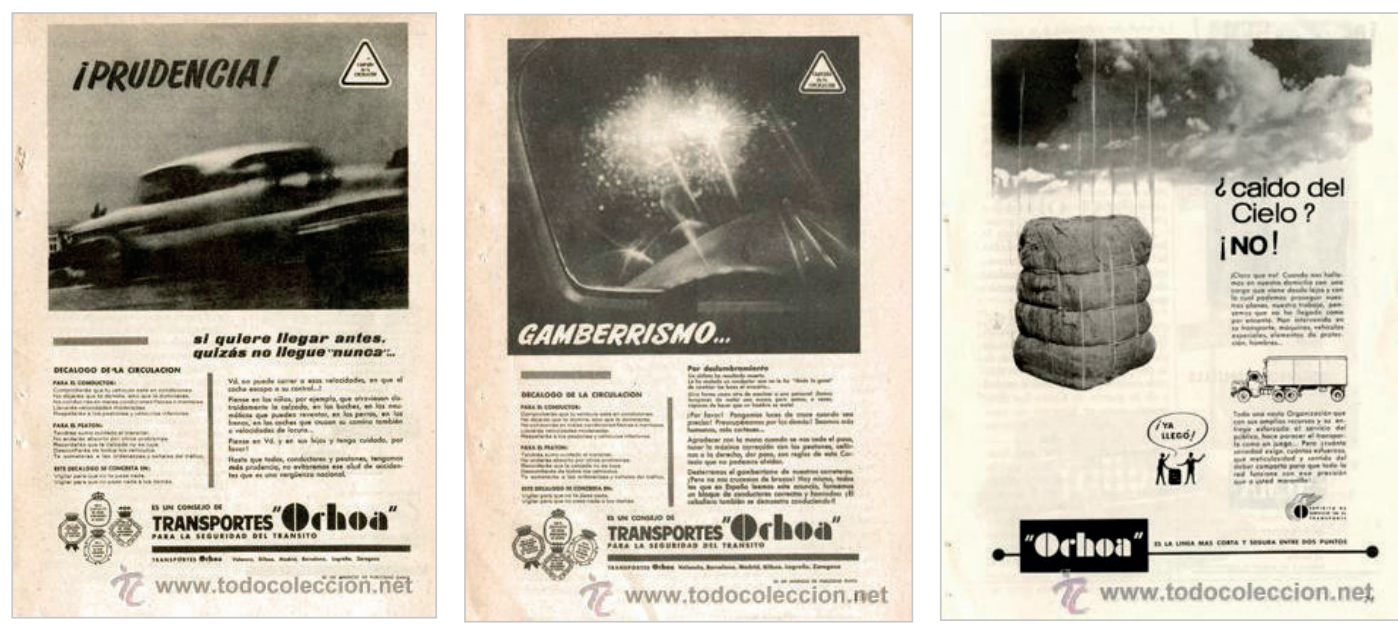

Imágenes 13, 14 y 15. Anuncios de la campaña de la circulación de Transportes Ochoa.

Fuente: $h$ ttp://www.todocoleccion.net 
Un poco más adelante las Relaciones Públicas alcanzan el nivel divulgativo y académico en 1962 que es cuando finalmente Fernando Lozano edita la Revista internacional de relaciones públicas, en 1964 (la primera publicación sobre publicidad es barcelonesa, de 1913 y se llamaba Comercio, dirigida por Prat Gaballí, y en 1914 se publica El heraldo mercantil en Madrid dirigida por Agustín Ungría).

El 1966 fue uno de los años más prolíficos en la historia de las RRPP en España. Uno de los acontecimientos más relevantes fue el I Congreso Español de Relaciones Públicas en Barcelona que coincidió con la XII Asamblea de la IPRA, en el que se ultimaron los detalles para constituirse el Cenerp-Madrid y el Cenerp-Barcelona. El 28 de mayo Pío Cabanillas Gallas (subsecretario de Información y Turismo) fue el encargado de clausurar dicho Congreso en el que participaron 167 congresistas, los primeros profesionales y teóricos de esta ciencia además de numerosos intelectuales de la época.

En 1967 se incluye la asignatura de Relaciones Públicas en la Escuela Oficial de Periodismo (la de Publicidad ya existía desde el 1955) y en la capital condal en 1969 se crea Eserp (Escuela Superior Empresarial de Relaciones Públicas) adscrita a la Universidad de Barcelona.

También en 1967 es modificado el Plan de Estudios de la Escuela de Periodismo para introducir la asignatura de Relaciones Públicas en el tercer curso, al mismo tiempo que las Cenerp de Madrid y Barcelona se separan creándose en esta última ciudad la Agrupación Española de Relaciones Públicas $(A E R P)$, con estatutos y órganos propios. Un año después la $A E R P$ cobra más importancia en el panorama internacional al ser elegida por la Asamblea Internacional Europea de Relaciones Públicas representante de los profesionales españoles de esta materia.

Tras esta pequeña crisis, que no afecta a la evolución de las Relaciones Públicas, aparece en la Universidad de Barcelona la Escuela Superior de Relaciones Públicas (febrero de 1968), que se reconoce oficialmente por el Boletín oficial del Estado justo un año más tarde. Empiezan a surgir nuevos centros de Relaciones Públicas en todo el territorio nacional, primero en Mallorca y luego en Málaga y Valencia. También en 1968 se publica el ejemplar número 9 de la colección de Ciencias Sociales del Instituto con el mismo nombre: "Sociología de las relaciones públicas".

En 1969, se celebra la I Asamblea Nacional de Relaciones Públicas en Madrid y en Barcelona la Asamblea Nacional del CERP y el II Congreso Internacional de Estudiantes de Relaciones Públicas (que finaliza con la creación de los estatutos de la Asociación Nacional de Estudiantes de RRPP). Se creó una Comisión Permanente que tuvo por misión velar por los acuerdos adoptados en la Asamblea Anual y la de ser el portavoz de la Asamblea en la Administración.

Comienza entonces la década de los 70. En esta década se intentó asentar y presentar a las personalidades políticas lo ya realizado anteriormente, a la vez que se llevaron a cabo nuevas innovaciones. En consonancia con lo primero, se presentó todo lo ya realizado por la Comisión Permanente y la Asamblea Nacional de Relaciones Públicas al ministro de Información y Turismo, José María Hernández Sampelayo. Esto se hizo a partir de un completo informe titulado El ordenamiento jurídico de las RRPP, algo que en aquel momento era muy necesario.

En octubre de 1970 la recientemente establecida en España agencia de Relaciones Públicas Hill \& Knowlton (quizá la más importante del mundo) realiza la primera encuesta específica sobre las Relaciones Públicas en España conjuntamente con el extinto diario Madrid. Se pretende conocer el estado de la opinión de los periodistas, publicistas, publirrelacionistas, estudiantes universitarios y hombres de negocios.

Ya en diciembre del 1970, el informe El ordenamiento jurídico de las Relaciones Públicas llegó a publicarse en el diario Madrid, en el que además se comentaron los resultados obtenidos. Dada su importancia, se decidió la creación de la Asamblea Nacional Sindical de Técnicos en Relaciones Públicas.

En 1971 se comienza a confeccionar un listado de profesionales de Relaciones Públicas recogido finalmente en la primera "Guía de Relaciones Públicas", editada por la AERP en el 1972. Esta misma asociación organiza la /l Semana de Cine de Relaciones Públicas y el Seminario de Relaciones Públicas para Seminarios. Se realizan nuevas reuniones de Asambleas, Grupos Sindicales y Conferencias. Un año más tarde, en 1972, nace de la mano del Sindicato Nacional de Prensa, Radio, Televisión y Publicidad la Agrupación Sindical de Técnicos en Relaciones Públicas en Madrid para regular el intrusismo profesional dado el gran aumento de profesionales.

En 1973, entre el 6 y el 9 de noviembre, se reúnen en Barcelona el Consejo de Dirección y el de Administración del Centro europeo de Relaciones Públicas. Se celebró la XI Semana Internacional de Ciencias Sociales a la que fueron invitados los miembros de la Administración. Su conferencia se centró en la "Comunicación en la gran ciudad".

Académicamente hay que citar que en 1974 se recoge en el plan de estudios de Publicidad de la Facultad de Ciencias de la Información de la Universidad Complutense la asignatura de Relaciones Públicas ${ }^{22}$ aunque hasta el plan de estudios del 1991 no alcanzan amplia representación las asignaturas de Relaciones Públicas, cuando se añade al concepto de Publicidad en la Licenciatura homónima ya existente, el de Relaciones Públicas, quedando como Licenciatura en Publicidad y Relaciones Públicas (Real decreto 1386/1991 de 30 de agosto). Castillo-Esparcia ha estudiado la implantación de las Relaciones Públicas en el ámbito universitario y la investigación que se lleva a cabo en esta disciplina. Según palabras del autor:

"A pesar de que los planes de estudio se encuentran implantados desde hace bastantes años, hasta los años 90 no se produce la gran mayoría de las tesis doctorales sobre Relaciones Públicas" (Castillo-Esparcia, 2010, p. 96). 
Hoy en día se tienden a impartir, en este Grado de Publicidad y Relaciones Públicas (que sustituyó a la Licenciatura) asignaturas y contenidos de comunicación corporativa (Corporate) gracias a la influencia de uno de sus redactores, Justo Villafañe, gurú de la comunicación corporativa española, quien habla de la

"nueva tendencia a transmitir atributos de identidad de las empresas a audiencias cada vez más fragmentadas, agrupadas en torno a valores, mucho más intangibles que los tradicionales criterios de segmentación de mercados, como los estilos de vida o los valores culturales" (Villafañe-Gallego, 1999, p. 220).

Finalmente, para Villafañe el Corporate, son

"todos aquellos aspectos, procedimientos, instrumentos, etc., que persiguen construir una determinada imagen corporativa (Miquel-Segarra; Navarro-Beltrá, 2016, p. 131).

Para Villafañe Corporate es un concepto que engloba todas las respuestas a las necesidades comunicativas de la empresa, se divide en cuatro parcelas:

"relaciones con la prensa, comunicación corporativa, comunicación del producto y comunicación interna" (Villafañe-Gallego, 1999, p. 11).

En 1974 se celebra el / Congreso Internacional de la Enseñanza y Práctica de las Relaciones Públicas en Barcelona y se funda la Asociación Iberoamericana de Relaciones Públicas gracias a una importante donación de la Revista de Relaciones Públicas.

En 1975 abre Jennings Public Relations SA a cuyo frente estaba Joaquín Fontes ya que su fundador, el norteamericano Bernard Jennings (1912-1985) no hablaba bien español. Era socio en España de la multinacional Burson-Marsteller de la que trataremos más adelante.

Un poco antes de la muerte de Franco, en 1975 se celebra el I Simposio Nacional de Relaciones Públicas y Protocolo en las Corporaciones Locales y se promulga el Real decreto 1092/1975 de 24 de abril por el que se establece el Registro oficial de técnicos en Relaciones Públicas bajo el control del Ministerio de Información y Turismo.

En 1976 se celebra la II edición del Simposio Nacional de Relaciones Públicas y Protocolo en las Corporaciones Locales.

En 1977 se celebran las III Jornadas Nacionales de Estudiantes de Relaciones Públicas (no hay constancia de las dos primeras) y se promulga el Real decreto 1201/1977 de 3 de mayo sobre el ejercicio de la actividad profesional. Se trata de unificar criterios y titulaciones para conocer a los técnicos de publicidad y Relaciones Públicas ya licenciados en las facultades de comunicación y regular su acceso a la profesión mediante la creación de Registros profesionales, lo que limitaría teóricamente el intrusismo.

Hay que esperar a 1978 para que se cree en Madrid el Colegio Profesional de Relaciones Públicas formado por directivos y ejecutivos de la misma rama.

Un hito en la historia de las Relaciones Públicas españolas se produce el 19 de julio de 1978 pues ese día José Luis Sanchís, licenciado en derecho y económicas, crea su agencia Sanchís y Asociados. Imagen y Comunicación, SA, especializándose en comunicación política, campañas electorales (ha trabajado con clientes como Francisco de Sá Carneiro, Adolfo Suárez, Manuel Fraga, Aníbal Cavaco Silva, Jordi Pujol, José Antonio Ardanza, Alberto Fujimori, Carlos Menem o Antonio Guzmán) y Corporate. Su importancia es capital en Relaciones Públicas políticas. Fue presidente mundial de la International Association of Political Consultants (IAPC), secretario general de la European Association of Political Consultans (EAPC) y miembro del Consejo Mundial de IPRA (International Association of Public Relations). Ya retirado, desde 2012 es presidente de honor de la consultora de comunicación Torres y Carrera.

El 16 de abril de 1978 se aprueba el Código de Lisboa como "Código Europeo de Conducta Profesional de Relaciones Públicas", en la asamblea general de la Confédération Européenne des Relations Publiques.

En 1979, tras la polémica y tensiones surgidas entre las asociaciones profesionales de Madrid y Barcelona es cancelado el /l Congreso Español de Relaciones Públicas en Barcelona.

Parta finalizar los 70 remarcaremos que el $B O E$ publicó un gran número de decretos por los que se regulaba la inscripción a los profesionales como Técnico de Relaciones Públicas (con cuota de 6.000 pesetas); también se creó el Premio Nacional de Relaciones Públicas "Baltasar Gracián", etc. (Caldevilla, 2007a).

Ya en los 80 con la colaboración del Ayuntamiento de Girona se celebró una importante reunión de las corporaciones locales sobre Relaciones Públicas organizada por el Instituto de Estudios de Administración Local.

También en 1980 se elaboraron unos nuevos estatutos adaptados a la legislación sobre asociaciones profesionales de la AISS y se confecciona un cuestionario para todos los colegios oficiales de abogados a fin de recoger información para realizar una ponencia que llevará por título "Las Relaciones Públicas en los Colegios de Abogados".

Del 26 al 29 de octubre de 1981 Luis López Ballesteros y Jesús Ulled participan como miembros españoles en una de las reuniones estatutarias de la International Public Relations Association (IPRA) en Madrid. 
El 4 de marzo de 1982 se aprueban los estatutos de la Asociación Catalana de Relaciones Públicas, quien, promovió por medio de su presidente, Javier Pérez Portabella la creación del Consejo Superior de Relaciones Públicas.

También en 1981 se produce la llegada oficial -oficiosamente desde 1979- de una de las principales multinacionales de la comunicación estratégica y Relaciones Públicas, con sede actual en Londres, Burson Mastellers de la mano de Teresa Dorn Stecker ${ }^{23}$, una profesional estadounidense que cambió las formas de hacer sectoriales y que sirvió de escuela a una generación de nuevos profesionales (Fernández-Agudo, 2013; Gómez-Baceiredo; Rodríguez-Salcedo, 2017).

En la revista Relaciones públicas y patrocinado por Fitur y la Dirección General de Correos, se publica el primer cómic acerca de las Relaciones Públicas en el 1983; en él aparecen Ángel Blanco como el bueno y Luis Ladino como el perverso (Caldevilla, 2007a).

En noviembre de 1983 se firma un acuerdo de colaboración entre el Consejo Superior de Relaciones Públicas en España y la Federación Interamericana de Asociaciones de Relaciones Públicas, bajo el espíritu de generar un

"sentido de futuro profesional común de Norteamérica y España".

La constitución no se formaliza hasta 1984 cuando se apertura la Conferencia Internacional de Relaciones Públicas (CIRP), en una solemne ceremonia efectuada en el Palacio Presidencial de Colombia (Bogotá).

Un año después, en 1984, da comienzo el I Congreso Iberoamericano de Relaciones Públicas, organizado por la Confederación Iberoamericana de Relaciones Públicas. De ambos fue presidente el uruguayo y renombrado cervantista Román Pérez Senac, padre de las Relaciones Públicas en su país y en Iberoamérica, fallecido en 2013.

En 1985 Carlos Paniagua funda Paniagua Consultores de Comunicación, empresa de referencia en España hasta hoy en día.

Su Majestad el Rey emérito Don Juan Carlos I recibe el nombramiento de Técnico de Honor en Relaciones Públicas en el año 1986.

En 1987 José Luis Arceo Vacas, profesor de la Universidad Complutense, fue elegido presidente de la Asociación de Doctores y Licenciados en Publicidad y Relaciones Públicas.

En 1987 y para celebrar su XX aniversario, la Escuela Superior de Relaciones Públicas (Eserp) de Barcelona creó la primera colección de libros de texto en la especialidad conocida actualmente como Comunicación y Relaciones Públicas. Esta colección tiene un gran valor documental y actualmente de ella parten muchas bibliotecas a la hora de comenzar sus recopilaciones para la materia que ahora nos ocupa. Las Relaciones Públicas comenzaron a recopilar más y más información justo en ese momento (Caldevilla, 2007a, p. 210).

En palabras de Luis Solano-Fleta (Caldevilla, 2002) la década de los 90 fue fundamental para las Relaciones Públicas porque en ella se asentaron las bases de lo que llamamos Relaciones Públicas actuales o modernas.

En enero de 1991 se inicia el proceso para la fundación de la Asociación de Empresas consultoras en Relaciones Públicas y Comunicación (Adecec), una de cuyas fundadoras fue Teresa Dorn, y se crea el Registro del censo de profesionales de Relaciones Públicas. Aproximadamente, las empresas asociadas a este organismo facturaron 2.500 millones de pesetas (15.000.000 €) y tenían en nómina a 250 empleados. Estos datos nos muestran el crecimiento del sector de las Relaciones Públicas, que había experimentado importantes cambios y avances sobre todo en la década de los 80.

Gómez-Baceiredo y Rodríguez-Salcedo (2017, p. 18) afirman que en 1990 por volumen de facturación, las cuatro primeras agencias españolas de Relaciones Públicas eran: Burson Marsteller (gracias a la obtención de la cuenta de la Expo 92), Ulled y Asociados, SAE de Relaciones Públicas y Hill \& Knowlton.

El 24 de noviembre de este año 1991 nace la Asociación Profesional de Directivos de Comunicación Social (ADC DirCom), constituida inicialmente por antiguos miembros del desaparecido Cenerp, como es el caso de Rafael Ansón Oliart ${ }^{24}$. En un principio la $A D C$ DirCom nace como una asociación civil sin ánimo de lucro, de ámbito nacional y establece su sede en Madrid. Por medio de este importante organismo se trata de impulsar el desarrollo de los estudios y las técnicas relativos a la comunicación, mediante colaboración de los docentes de Ciencias de la Información. Ramón Díez del Corral se convierte en su primer presidente (Caldevilla, 2007a, p. 211).

Del 2 al 4 de agosto de 1994 tiene lugar en El Escorial el primer curso de verano de la Universidad Complutense en colaboración con ADC DirCom bajo el título 'El Director de Comunicación en la empresa actual'. Este curso tiene un gran éxito y es el primero de otros muchos.

En 1995 Luis Solano-Fleta publica "Fundamentos de las Relaciones Públicas", el primer libro académico que ofrece una visión estructural de las mismas, considerándolas como ciencia y no como meras técnicas, lo que le convierte en el clásico por excelencia de la materia.

El 5 de noviembre del 1998 se aprueba la Ley 12/1998 para la Creación del Colegio de Publicitarios y Relaciones Públicas de Cataluña en el Parlamento Catalán tras más de un año de reuniones de la Comisión Gestora formada por representantes del sector y la Administración catalana. Esto es consecuencia inmediata de la unificación de las profesiones de Publicidad y Relaciones Públicas primeramente en las universidades (desde 1992 la titulación de Publicidad y Relaciones 
Públicas) y también en muchas empresas globales multinacionales. Además, esta unificación se produce también por la importancia que cobran estas dos profesiones a la hora de crear riqueza en numerosas empresas nacionales e internacionales. La creación del colegio profesional es, además de un triunfo para las Relaciones Públicas, "un nuevo impulso y reconocimiento a la profesión" desde las primeras regulaciones profesionales de la década de los 50; debido a lo cual la Generalitat catalana aprobó un decreto, el 183/1999 para derogar las disposiciones sobre los registros de empresas y actividades publicitarias y de profesionales de las Relaciones Públicas (Caldevilla, 2007a, p. 211).

Esto llevó a la creación del primer Colegio de Publicitarios y Relaciones Públicas con sede en Barcelona y de ámbito catalán. En noviembre de 1999 se aprueban los estatutos del Colegio Profesional en la primera Asamblea General. En la Asamblea Constituyente no fue aceptada la creación de dos ámbitos en sinergia, pero sí ayudó a clarificar la actividad de la publicidad como diferenciada de las Relaciones Públicas en tres vertientes bien diferentes de esta ciencia: la vertiente filosófica, la teórica y la práctica. Sus miembros son historia viva de las Relaciones Públicas en España (Ferrán Martorell -director de la Comisión-, Francesc Oteo -secretario general-, Mónica Cabarrocas y Víctor Ayala entre otros).

En el curso 1998-1999 la Escuela Superior de Relaciones Públicas de Barcelona (Eserp) comienza a impartir por primera vez en España, un curso de Graduado en Relaciones Públicas y Comunicación de las Organizaciones.

En el informe anual firmado por Villafañe-Gallego (1999) sobre El estado de la publicidad y el Corporate en España y Latinoamérica correspondiente a 1998, ya se manifestaba que en ese año el $68 \%$ de las empresas consideraba la comunicación como un factor estratégico, mientras que el 30\% la valoraba como a cualquier otra dirección y el $2 \%$ sólo recurría a la comunicación en ocasiones puntuales.

En la versión del año 2000 de "El estado de la publicidad y el corporate en España y Latinoamérica” (Villafañe-Gallego, 2001) se afirmaba que ya existía la conciencia de que la comunicación era una herramienta básica. De hecho se constataba que el $76 \%$ de las empresas ya contaban con la figura de director de comunicación y con un presupuesto específico destinado a comunicación. En 2000 se crea el Ilustre Colegio Oficial de Publicitarios y Relaciones Públicas de la Comunidad Valenciana (no obstante para trabajar profesionalmente en el campo de la Publicidad y Relaciones Públicas no es necesario estar inscrito).

Y comienza el siglo XXI donde convenimos con Miquel-Segarra et al. (2018, p. 482) en que

"a pesar de no estar recogida toda la realidad empresarial de la consultoría de comunicación y Relaciones Públicas, los datos del Instituto Nacional de Estadística ponen de manifiesto que después de unos años de descenso, existe una recuperación significativa en el sector de las Relaciones Públicas [en la década de los 10 del siglo XXI]".

Hoy en día las Relaciones Públicas se han adaptado a lo que Vázquez-Cano et al. (2016, p. 596) definen como

"Ios nuevos estilos de contar los contenidos que difieren en su soporte y su forma, condicionando el propio entorno del mensaje y su significado. Así surgen los micromensajes tipo tuit, y otros elementos modalizadores asumidos en el discurso, pero no esenciales para su construcción, tales como los elementos paralingüísticos"

en los que encontramos lo que McLuhan definió como El medio es el mensaje, lo que dio título a su más afamado libro en 1967.

El futuro del sector se presagia positivo ya que la saturación de los medios tradicionales y la mejor relación coste-efectividad de la consultoría de comunicación son los factores que harán crecer este sector. Sin embargo, reconoce el estudio de Adecec que existen dos factores que limitan el crecimiento:

- la falta de definición clara de las actuaciones específicas, y

- la dificultad de encontrar buenos profesionales (Caldevilla, 2007a).

Por otro lado, el uso de herramientas relacionadas con las nuevas tecnologías está modificando a pasos agigantados la profesión y las funciones del Relaciones Públicas en todas sus facetas y roles de actuación.

\section{Conclusiones}

Hay una frase que define perfectamente lo que debe ser la filosofía empresarial: "Hacer las cosas bien, y hacerlo saber", tal y como propuso el periodista estadounidense Ivy Ledbetter Lee en sus comienzos como primer publirrelacionista. Tal es así que Federico Revilla en 1992 tituló con el espíritu de este rubro su libro más famoso

\section{Las Relaciones Públicas presentan una serie muy variada de elementos para permitir que la máxima Hacerlo bien y hacerlo saber se produzca}

Hacerlo bien y hacerlo saber: Relaciones Públicas de la Empresa. El hacerlo bien es competencia de los trabajadores pero el hacerlo saber se delega cada vez más en profesionales publirrelacionísticos, incluso si éstos no tienen conciencia plena de su naturaleza o de adscripción a esta profesión.

De la investigación desarrollada en el presente artículo se derivan dos grandes conclusiones:

1) Las Relaciones Públicas presentan una serie muy variada de elementos para permitir que la máxima Hacerlo bien y hacerlo saber se produzca, con herramientas como la mercadotecnia, la publicity, la propaganda, la publicidad, la pro- 
paganda, la comunicación interna, la comunicación corporativa (que también se sirve de contenidos a su vez de los demás elementos), la prospectiva, el cabildeo..., que venían siendo aplicados, quizá sin un orden ni estrategias bien definidas desde hace aproximadamente un siglo en España (y por ende en Europa), por tanto antes del desembarco de las bases militares estadounidenses (1953) en España.

2) También afirmamos que las Relaciones Públicas son persuasivas en su esencia más nuclear, admitiendo que el tratar de construir puentes de mutua comprensión entre los públicos y el emisor de la comunicación es importante pero no una finalidad en sí, sino que demostramos que se trata de una estrategia más a tal objetivo final.

Esto ha quedado demostrado por las ingentes labores de los adelantados Prat Gaballí y García Ruescas, aunque no sean los únicos en este panorama inicial, que desarrollaron antes del propio concepto, las Relaciones Públicas en España principalmente desde el campo de la Publicidad y desde el de la Propaganda.

A la par, aunque con un poco de retardo, hemos demostrado que tanto el mundo gremial, plasmado en asociaciones o grupos cohesionados estatutariamente, así como el mundo académico (merced a libros impresos o a planes de estudio) se han ido sumando a esta nueva corriente llamada Relaciones Públicas, de manera que su importancia es cada vez mayor, derivada de la toma de conciencia que se ha producido en las empresas, antes grandes y ahora ya pymes, sobre la necesidad de una gestión profesional de su comunicación. Las dotaciones de recursos humanos y presupuesto no han hecho sino aumentar desde su origen.

Finalmente, y como consecuencia de lo anterior, concluiremos que los contenidos de las campañas de finales del siglo $X X$, el siglo que vio nacer las Relaciones Públicas profesionales, y cuya onda gravitatoria aún se siente en este siglo XXI, se enmarcan cada vez más en un concepto que puede ser llamado como comunicación corporativa 360․ Humanidad, inteligencia emocional y persuasión son elementos que pueden darse como imprescindibles para desarrollar las Relaciones Públicas de manera ética y con altos niveles de calidad superando las expectativas de aquellas personas o instituciones que confían en la labor de las mismas.
Los contenidos de las campañas se enmarcan cada vez más en un concepto que puede ser llamado como comunicación corporativa 360응

\section{Notas}

1. Publicity es la información que emite una empresa u organismo, generalmente a través de su gabinete de prensa, a fin de hallar eco en los medios de comunicación y conseguir una mejora en su imagen de marca o labores desempeñadas. La versión clásica siempre ha considerado que debe ser gratuita, pero en nuestra opinión actualmente mucha publicidad enmascarada como información, que es la base de la publicity, también comprendería alguna contraprestación económica. La empresa/marca gana credibilidad por emitir un mensaje que simula una información respaldada por el medio.

2. La International Public Relations Association (IPRA) fue fundada en Londres en 1955.

3. La Federación Interamericana de Asociaciones de Relaciones Públicas, fundada en México D.F. en 1960, organizó la I Asamblea Mundial de Asociaciones de Relaciones Públicas desde donde emanó el 'Acuerdo de México' de agosto del 1978 en el que se ofreció una definición común para los países de la Lengua:

“El ejercicio profesional de las Relaciones Públicas exige una acción planteada con apoyo de la investigación en la comunicación sistemática y en la participación programada, para elevar el nivel de entendimiento, solidaridad y colaboración entre una entidad pública o privada y los grupos sociales a ella vinculados, en un proceso de integración de intereses legítimos, para promover su desarrollo recíproco y el de la comunidad a que pertenece".

4. A su pluma se deben dos textos sobre la guerra civil española en 1937, ya que Goebbels hizo de propagandista en Alemania para Franco: “Libro Rojo sobre España" (centrado en el terror rojo) y su discurso "La verdad sobre España" pronunciado en Núremberg durante el congreso del partido nazi en el que referenciaba la lucha del fascismo positivo de Franco frente al imperialismo judío-bolchevique.

5. En 1928 se abrió el primer Parador Nacional de Turismo en Sierra de Gredos (Ávila).

6. Actualmente el mayor galardón otorgado en dicho certamen lleva su nombre.

7. Destacamos que en 1962 ganó Raphael, contando 17 años, con 'Llevan' y en 1968 Julio Iglesias, de 25 años, con 'La vida sigue igual'. Chile se apuntó a esta forma de Relaciones Públicas y creó en 1960 el Festival de la Canción de Viña del Mar, su Marbella.

8. Juan Viñas Bona (Girona 1918-Barcelona 2002) fue miembro de la Federación de Jóvenes Cristianos de Cataluña, movimiento de Acción Católica. Terminada la guerra civil en la que luchó en el bando franquista fue nombrado en 1940 Delegado de prensa y propaganda. Fue una voz destacada en Radio Nacional de España.

9. Se trata de una obra lujosamente presentada, editada con motivo del 750 aniversario de la edición del primer libro sobre publicidad en lengua española por la Cámara de Comercio de Barcelona. 
10. Pedro Prat Gaballí (1885-1962) es uno de los primeros estudiosos del fenómeno publicitario en España, con títulos como Publicidad racional (1934) o Publicidad combativa (1959), y uno de los adelantados de las Relaciones Públicas nacionales tanto en su aplicación como en su estudio. Su biografía está magníficamente recogida por tres artículos de los números 6 y 7 de la revista Publifilia: Revista de culturas publicitarias titulados "El arte al servicio de la técnica" en 2002, y en 2003 “Los años del 'arte comercial'” y "Vidas de anuncio: Emeterio R. Melendreras" firmados por el riojano Raúl Eguizábal, de la UCM.

11. El departamento de publicidad estaba formado por cuatro trabajadores más un administrativo. Inicialmente se cita a Ribas como director artístico, al periodista Emiliano Ramírez Ángel, redactor de textos y creativo, Prat Gaballí en la dirección, el cuarto nombre por el momento queda en el olvido de los historiadores, aunque ya en Véritas trabajaron Gómez Acebo, Espada y el dibujante, admirado por Prat, Emilio Ferrer, quien también estuvo en Oeste.

12. Ribas, recién llegado de París, se convirtió en director artístico de la Casa Gal desde 1916, cuando ésta convocó un concurso de carteles para promocionar su jabón Heno de Pravia y lo ganó.

13. Recordemos que la II República española (1931-1939) trajo un aire renovador de modernización en lo social, material y espiritualmente.

14. Según Pérez-Ruiz (2003, p. 45) cerca de un 70\% de la facturación en medios lo acaparaban las agencias Alas, Cid, Publicitas, La Universal, Gisbert, Ruescas Publicidad y Atlantis.

15. Con sede en la Av. Diagonal barcelonesa, creó la Danis City, que incluía un centro comercial. Tuvo delegaciones en Bilbao y Madrid. Tras su internacionalización con asociaciones estratégicas en Francia y Estados Unidos, se unió a $B \& B$ y luego se uniría a D’Arcy, formando $D B \& B$.

16. Básicamente eran tres productos: detergente Lavasol, lavavajillas Mistol y su primer producto, lejía Guerrero.

17. Matrat bebe de las fuentes de los clásicos estadounidenses como Bernays, Cutlip y Center, Canfield, Berelson, Grunig, Lesly..., pero se caracteriza por su humanismo que hace que ubique el concepto de confianza como elemento nuclear de su pensamiento (Xifra-Triadú, 2006).

18. Pacto firmado el 26 de septiembre de 1953 con los EUA por el que se cedían 9 bases militares en España de las que sólo se materializaron las 4 actuales: Zaragoza, Rota, Morón y Torrejón.

19. Tan ridícula fue la ayuda (de material de desecho de la guerra de Corea) que incluso en la Guerra de Ifni (1957-58) a España se le prohibió emplear dicho material contra los marroquíes y la aviación empleada en el frente era la que quedaba de la ayuda hitleriana a Franco en la Guerra Civil. Hubo 386 muertos, 578 heridos y 80 desaparecidos.

20. Renfe quería cambiar su imagen de impuntualidad y mal servicio. Incluso se hizo un chiste con sus siglas: Retraso Enorme, Necesitamos Fuerzas, Empujen (en realidad REd Nacional de Ferrocarriles Españoles).

21. Instituto Nacional de Industria (creado en 1941 y actualmente llamada Sociedad Estatal de Participaciones Industriales, SEPI), que aglutinaba a las más importantes empresas industriales estratégicas del país.

22. Dos decretos del Ministerio de Educación y Ciencia regulan la creación de los estudios específicos y de las Facultades de Ciencias de la Información. Por Decreto 2070/71, de 13 de agosto, se regulan los estudios de Periodismo y demás Medios de Comunicación Social en la Universidad y por Decreto 2478/71, de 17 de septiembre, se crean las Facultades de Ciencias de la Información en la Universidad Complutense de Madrid y en la Universidad Autónoma de Barcelona. La única diferencia existente entre ambas universidades estriba en que en Barcelona se instaura sólo la rama de Periodismo, mientras que en la Complutense se establecen las tres licenciaturas que existen como grado en la actualidad: Periodismo, Ciencias de la Imagen Visual y Auditiva y Publicidad -sin mencionar Relaciones públicas-, hoy denominadas: Grado en Periodismo, Grado en Comunicación Audiovisual y Grado en Publicidad y Relaciones Públicas.

23. Previamente (1974-75) había trabajado para la empresa de Javier Maestre, SAE de Relaciones Públicas, y en el periodo 1975-79 para Jennings Public Relations, consorciado en España de Burson Mastellers para la que trabajó desde 1979.

24. Rafael Ansón Oliart (San Sebastián, 1935-). Fue miembro del Cuerpo de Técnicos de Información y Turismo. Posteriormente director del Instituto de la Opinión Pública, precursor del actual CIS. Entre julio de 1976 y noviembre de 1977 fue director de RTVE. En febrero de 1978 pasó a ejercer la presidencia de la Coordinadora de Asociaciones Profesionales de la Comunicación Social. Preside la Fundación de Estudios Sociológicos.

\section{Referencias}

Academia de la Publicidad (2011). Web de la Academia de publicidad. http://www.academiadelapublicidad.org/la-academia

Agencia de Publicidad Danis (1956). Catálogo. Unos anuncios diferentes de Mistol y Lejía Guerrero. Barcelona: Publicidad Danis.

Agencia Linares (2012). Blog 'Evolución de las Relaciones públicas'.

http://evoluciondelasrrpp.blogspot.com 
Almansa-Martínez, Ana (2004). "Historia de los gabinetes de comunicación en España”. Historia y comunicación social, n. 9, pp. 5-21.

https://revistas.ucm.es/index.php/HICS/article/view/HICS0404110005A/19269

Almansa-Martínez, Ana (2005). "Relaciones públicas y gabinetes de comunicación”. Anàlisi. Quaderns de comunicació i cultura, n. 32, pp. 117-132. https://core.ac.uk/download/pdf/38977160.pdf

Almansa-Martínez, Ana (2011). Del gabinete de prensa al gabinete de comunicación: la dirección de comunicación en la actualidad. Zamora: Comunicación Social y Publicaciones. ISBN: 9788492860906

Álvaro, Eduardo; Antona, Sara; Arias, Elías; Burghiu, Denisa; Campanero, Lucía (2016). Prat Gaballí y la revista Fama. http://www.youtube.com/watch?v=9NfaWA58rv8

Andrés-Gallego, José (2003). Esquilache y los jesuitas.

http://joseandresgallego.com/docs/MotinEsquilAmEur091Pesquisa.pdf

Angosto-Vélez, Pedro-Luis (2001). Sueño y pesadilla del republicanismo español. Carlos Esplá: una biografía política. Madrid: Editorial Biblioteca Nueva. ISBN: 847030965X

Anónimo (2016). Homenaje de la agencia J. Walter Thompson

http://www.youtube.com/watch?v=K7AYqiGaWMY

Anónimo (2016). Homenaje de la agencia Grey a la Agencia Fama.

http://www.youtube.com/watch?v=wdG0Tnhly50.

Arceo-Vacas, José-Luis (1988). Fundamentos para la teoría y técnica de las relaciones públicas. Barcelona: ESRP-PPU. ISBN: 8476653646

Arceo-Vacas, José-Luis (2004). La teoría de las relaciones públicas en España. Las relaciones públicas en España. Parte II. Madrid: McGraw-Hill, pp. 49-112. ISBN: 9788448141837

Arceo-Vacas, José-Luis (2006). "La investigación de relaciones públicas en España”. Anàlisi. Quaderns de comunicació $i$ cultura, n. 34, pp. 111-124.

http://www.raco.cat/index.php/Analisi/article/view/55447/64579

Armendáriz, Enrique (2012). "Relaciones públicas pioneras en España. Algunos precedentes en la primera mitad del siglo XX y pasos preliminares de la nueva profesión". Anàlisi. Quaderns de comunicació i cultura, n. 45, pp. 15-31. https://analisi.cat/article/view/n45-armendariz/n45-armendariz

Barjau, Santi (s/f). Blog els meus cartel.listes.

http://cartellistes.blogspot.com/2014/08/la-fama-esquiva-de-robert-cartes-per.html

Barquero-Cabrero, José-Daniel (2002). Comunicación y Relaciones Públicas. Madrid: McGraw Hill. ISBN: 9788448132194

Barrientos-Báez, Almudena (2018). Las emociones y su incidencia en la formación de los estudiantes de Turismo en España. Innovación universitaria: Digitalización 2.0 y excelencia en contenidos, pp. 71-88. Madrid: McGraw-Hill Education. ISBN: 9788448615031

https://dialnet.unirioja.es/servlet/articulo?codigo $=6877010$

Barrientos-Báez, Almudena (2019). El desarrollo de la inteligencia emocional en los estudios del Grado en Turismo en la Universidad de La Laguna (Tenerife). Tesis doctoral. Universidad Camilo José Cela, Madrid.

https://repositorio.ucjc.edu/handle/20.500.12020/863

Beneyto-Pérez, Juan (1957). Mass communications. Un panorama de los medios de información en la sociedad moderna. Madrid: Instituto de Estudios Políticos.

Beneyto-Pérez, Juan (1961). Teoría y técnica de la opinión pública. Madrid: Tecnos.

Beneyto-Pérez, Juan (1973). Mass communications. Un panorama de los medios de información en la sociedad moderna (Edición revisada y ampliada). Madrid: Instituto de Estudios Políticos.

Beneyto-Pérez, Juan (1979). “La política de comunicación en España durante el franquismo”. Revista de Estudios Políticos, n. 11, pp. 157-170.

https://dialnet.unirioja.es/servlet/articulo?codigo=1273269

Bentele, Günter; Szyska, Peter (1995). PR-Ausbildung in Deutschland. Entwicklung, Bestandsaufnahme und Perspektiven. Deutschland: Opladen. ISBN: 9783322942050

Cabrera-Cabrera, María-Ángeles; Almansa-Martínez, Ana (2016). "El director de relaciones públicas en las grandes empresas españolas". Revista internacional de relaciones públicas, v. 6, n. 11.

https://doi.org/10.5783/RIRP-11-2016-07-113-134 
Cal-Martínez, María-Rosa (1997). “La propaganda del turismo en España. Primeras organizaciones”. Historia y comunicación social, n. 2, pp. 125-133.

https://revistas.ucm.es/index.php/HICS/article/view/HICS9797110125A/19898

Caldevilla-Domínguez, David (2002). Entrevista a D. Luis Solano Fleta, $1^{\text {er }}$ Catedrático en España de Relaciones Públicas en la Universidad Complutense de Madrid (Archivo sonoro). Madrid: Fórum XXI.

Caldevilla-Domínguez, David (2005a). Relaciones públicas y su fundamentación. Madrid: Visionnet. ISBN: 97884 97708913

Caldevilla-Domínguez, David (2005b). Relaciones públicas y cultura. Madrid: Visionnet. ISBN: 9788498217179

Caldevilla-Domínguez, David (2007). Manual de relaciones públicas. Madrid: Visionnet. ISBN: 9788498217049

Caldevilla-Domínguez, David (2009). "Las relaciones públicas como herramienta de la prospectiva”. Vivat academia, n. 106, pp. 1-20.

https://doi.org/10.15178/va.2009.106.30-49

Caldevilla-Domínguez, David (2010). La cara interna de la comunicación en la empresa. Madrid: Visión libros. ISBN: 978 8499839158

Campos-García-de-Quevedo, Gloria; Fuente-Lafuente, Carlos (2013). "Los eventos en el ámbito de la empresa. Hacia una definición y clasificación". Revista de comunicación de la SEECI, n. 32, pp. 73-105.

https://doi.org/10.15198/seeci.2013.32.73-105

Campos-Zabala, María-Victoria (1999). “El Portavoz del Gobierno: orígenes, evolución, funciones y consolidación. El desarrollo de la administración comunicativa en España”. Tesis doctoral. Madrid: UCM.

https://eprints.ucm.es/3820/1/T23814.pdf

Canfield, Bertrand (1962). Relaciones públicas: principios, casos, problemas. Buenos Aires: Mundi. ISBN: 47756183

Castillejo, Rafael (s/f). Blog el desván de Rafael Castillejo.

http://www.rafaelcastillejo.com/cosas-3.htm

Castillo-Esparcia, Antonio (2001). Los grupos de presión ante la sociedad de la comunicación. Servicio de Publicaciones de la Universidad de Málaga. ISBN: 8474969131

Castillo-Esparcia, Antonio (2009). Relaciones públicas, teoría e historia. Barcelona: Editorial UOC. ISBN: 9788497888172

Castillo-Esparcia, Antonio (2010). Introducción a las relaciones públicas. Málaga: Instituto de investigación en Relaciones Públicas. ISBN: 9788461424481

http://www.uma.es/media/files/libropr_1.pdf

Centro de Documentación Publicitaria (s/f).

http://www.lahistoriadelapublicidad.com

Checa-Godoy, Antonio (2005). Las rutas de la publicidad en Andalucía. Sevilla: Fundación José Manuel Lara. ISBN: 8496152928

Correyero-Ruiz, Beatriz (2003). "La propaganda turística española en los años del aislamiento internacional". Historia y comunicación social, n. 8, pp. 47-61.

https://revistas.ucm.es/index.php/HICS/article/view/HICS0303110047A/19327

Cutlip, Scott-Munson; Center, Allen H. (1972). Relaciones públicas. Madrid: Rialp. ISBN: 9788432110733

Cutlip, Scott-Munson; Center, Allen H. (2001). Relaciones públicas eficaces. Barcelona: Gestión 2000. ISBN: 97884 80885737

De-Urzáiz-y-Fernández-del-Castillo, Jaime (1971). Teoría técnica de las relaciones públicas. Madrid: San Martín. ISBN: 9788471400024

De-Urzáiz-y-Fernández-del-Castillo, Jaime (1977). Ordenación de las relaciones públicas. Madrid: Instituto Nacional de Publicidad. ISBN: 8485304063

Denig, Eric (2000). "At the turn of the century. Development of public relations in the Netherlands". In: E. Denig; A. Weisink (eds.). Challenges in communication. State of the art \& future trends, pp. 29-37. IPRA Gold Paper n. 13. GB Esher: IPRA.

Desantes-Guanter, José-María (1979). “Los conceptos de propaganda, publicidad y relaciones públicas”. En VV.AA. Inauguración del Instituto de la Comunidad Social, pp. 13-33.

Eguizábal-Maza, Raúl (1998). Historia de la publicidad. Madrid: Eresma-Celeste. ISBN: 9788482111605 
Eguizábal-Maza, Raúl (2002). “El arte al servicio de la técnica”. Publifilia: Revista de culturas publicitarias, n. 6, pp. 65-68. Eguizábal-Maza, Raúl (2003a). “Los años del 'arte comercial'”. Publifilia: Revista de culturas publicitarias, n. 7, pp. 43-64. Eguizábal-Maza, Raúl (2003b). “Vidas de anuncio: Emeterio R. Melendreras”. Publifilia: Revista de culturas publicitarias, n. 7, pp. 91-96.

Fombona-Cadavieco, Javier; Goulão, María-de-Fátima; García-Tamargo, Marco-Antonio (2014). "Melhorar a atratividade da informação a través do uso da realidade aumentada". Perspectivas em ciencia da informação, v. 19, n. 1, pp. 37-50.

https://doi.org/10.1590/s1413-99362014000100004

Fontcuberta-Vernet, Joan (1998). Hora cero. Barcelona: Editorial Thassàlia. ISBN: 9788482370873

García-Ruescas, Francisco (1971). Historia de la publicidad en España. Madrid: Editora nacional.

García-Ruescas, Francisco (1995). Relatos al final del camino. Madrid: Diamer.

Gómez-Baceiredo, Beatriz; Rodríguez-Salcedo, Natalia (2017). "Teresa Dorn, trabajo y serendipia”. Revista nuevas tendencias, n. 98.

https://dadun.unav.edu/bitstream/10171/54411/1/04.pdf

Grunig, James E. (1992). Excellence in public relations and communication management: Contributing to effective organizations. Hillsdale, N.J.: Lawrence Erlbaum Associates. ISBN: 9783531156026

Gutiérrez-García, Elena; Rodríguez-Salcedo, Natalia (2009). “Cincuenta años de relaciones públicas en España. De la propaganda y la publicidad a través de la gestión de la reputación”. Doxa comunicación, n. 9, pp. 9-33.

https//doi.org/10.31921/doxacom.n9a1

Indira Gandhi National Open University, India (2019). Public relations program JMC-04.

http://www.ignouhelp.in/ignou-jmc-04-study-material

Lagerwey, Eric; Hemels, Joan M. H. J.; Van-Ruler, Betteke (1997). Op zoek naar faamwaarde. Vijftig jaar public relations in Nederland. Houten: Bohn Stafleu Van Loghum. ISBN: $903132180 \mathrm{X}$

Lesly, Philip (1981). Nuevo manual de relaciones públicas. Madrid: Martínez de Roca. ISBN: 9788427006430

L'Etang, Jacquie (1999). "Public Relations education in Britain: An historical review in the context of professionalisation". Public relations review, v. 25, n. 3, pp. 261-289.

https://doi.org/10.1016/S0363-8111(99)00019-3

López-Castro, Jesús (2005). "Historia de las relaciones públicas en España". En: Barquero Cabrero, José Daniel; Barquero Cabrero, Mario. Manual de relaciones públicas, comunicación y publicidad. Barcelona: Gestión 2000, pp. 517-562. ISBN: 9788496426061

Marqués-Carbó, Luis; Marqués-Canós, Luis G. (1958). Las relaciones públicas en el ámbito local. Barcelona: Marqués Canós.

Martín-García, Mercedes (1999). Historia de las relaciones públicas.

http://www.ignouhelp.in/ignou-jmc-04-study-materialwww.rrppnet.com.ar/historiadelasrrpp.htm

Míguez-González, María-Isabel; Baamonde-Silva, Xosé-Manuel (2011). "La evolución de las relaciones públicas hacia la dirección de comunicación. Aproximación histórica en el contexto académico español”. Razón y palabra, n. 75, pp. 1-13. http://www.razonypalabra.org.mx/N/N75/varia_75/varia2parte/13_Miguez_V75.pdf

Miquel-Segarra, Susana; López-Font, Lorena; Gil-Soldevila, Samuel (2018). “Radiografía de las consultoras de comunicación en España: perfil profesional, estructura y actividad". Revista latina de comunicación social, n. 73, pp. 478-503. https//doi.org/10.4185/RLCS-2018-1266

Miquel-Segarra, Susana; Navarro-Beltrá, Marián (2016). "Análisis de la investigación sobre la historia y evolución de las relaciones públicas y la comunicación corporativa en España”. Doxa Comunicación, n. 22, pp. 129-146. https://doi.org/10.31921/doxacom.n22a6

Molina-Cortés, Inés (2015). Prat Gaballí.

http://www.ignouhelp.in/ignou-jmc-04-study-materialwww.youtube.com/watch?v=9S8lgw1kra8

Montero-Díaz, Mercedes; Rodríguez-Salcedo, Natalia; Verdera-Albiñana, Francisco (2010). De la nada al consumo: desde los orígenes hasta 1960. Historia de la publicidad y de las relaciones públicas en España, v. 1. Sevilla, Zamora: Comunicación Social. ISBN: 9788492860586

Mora-Canela, Juan-Ramón (s/f). Blog de Juan Ramón Mora Canela. "Cuando se dibujaba la publicidad". http://www.jrmora.com/blog/2009/07/20/de-cuando-se-dibujaba-la-publicidad 
NODO (1957). Número 631.

http://www.rtve.es/alacarta/videos/revista-imagenes/dos-ojos-para-toda-vida-cruzada-proteccion-ocular/2868497

Noguero-Grau, Antoni (1982). Relaciones Públicas e industria de la persuasión. Barcelona: Eunibas. ISBN: 97884 76654569

Noguero-Grau, Antoni (1985). Programación y técnicas de las Relaciones Públicas. Barcelona: Ediciones Universitarias PPU. ISBN: 9788489607682

Noguero-Grau, Antoni (1994). “La historia de las relaciones públicas en España: 1954-1990”. Revista universitaria de publicidad y relaciones públicas, n. 1, pp. 67-90.

Noguero-Grau, Antoni (1995). La función social de las relaciones públicas: historia, teoría y marco legal. Barcelona: ESRP-EUB. ISBN: 9788447705153

Oliveira-dos-Santos-Augusto, Manuel-Alfredo (2009). “A comunicação institucional e o papel das relações públicas e do protocolo na sociedade contemporánea". Vivat academia, n. 107 julio-agosto, pp. 103-155.

https://doi.org/10.15178/va.2009.107.103-155

Paniagua-Gallart, Carlos (2012). Apuntes para una historia de la comunicación y las Relaciones Públicas en España. http://www.topcomunicacion.com/historia-de-la-comunicacion-y-relaciones-publicas-espana-carlos-paniagua

Pérez-Ruiz, Miguel-Ángel (2003). La transición de la publicidad española: anunciantes, agencias, centrales y medios (1950-1980). Madrid: Fragua. ISBN: 8470741365

Piñeiro-Otero, María-Teresa (2005). "El cancionero de la Guerra Civil. Propaganda y contrapropaganda sonora”. Revista de comunicación de la SEECI, n. 12, pp.108-146.

https://doi.org/10.15198/seeci.2005.12.108-146

Prat-Gaballí, Pedro (1934). Publicidad racional. Barcelona: Labor.

Prat-Gaballí, Pedro (1959). Publicidad combativa. Barcelona: Labor.

Reina-Estévez, Jesús (2015). "Antecedentes de relaciones públicas en la prensa malagueña de principios del siglo XX". Ámbitos: revista internacional de comunicación, n. 27, pp. 51-60.

https://institucionales.us.es/ambitos/antecedentes-de-relaciones-publicas-en-la-prensa-malaguena-de-principios-delsiglo-xx

Reina-Estévez, Jesús; González-España, María-Inmaculada (2014). “Antecedentes de relaciones públicas en los manuales de publicidad. Algunos precedentes de actividad en España desde mediados del siglo XIX". Vivat academia, n. 128, pp. 1-20.

https://doi.org/10.15178/va.2014.128.1-20

Rodríguez-Salcedo, Natalia (2007). "La historia como tendencia actual de las relaciones públicas”. En: Congreso tendencias actuales de las relaciones públicas de la AIRP. https://idus.us.es/xmlui/bitstream/handle/11441/38790/Actas-II-Congreso-AIRP.pdf

Sagarminaga-Gutiérrez, Naiara; Canals-Parera, Agustí (2011). “Recuperación y tratamiento de opinión movilizada para el análisis del clima social”. El profesional de la información, v. 20, n. 5, pp. 510-515.

https://doi.org/10.3145/epi.2011.sep.04

Saladrigas-Medina, Hilda (2005). “Comunicación organizacional: Matrices teóricas y enfoques comunicativos". Revista latina de comunicación social, n. 60.

http://www.ull.es/publicaciones/latina/200540saladrigas.htm

Sentís-Anfruns, Carlos (2006). Memorias de un espectador (1911-1950). Barcelona: Ediciones Destino. ISBN: 97884 23339634

Solano-Fleta, Luis (1995). Fundamentos de las relaciones públicas. Madrid: Síntesis. ISBN: 8477383146

Solano-Fleta, Luis (1999). Tratado de relaciones públicas. Barcelona: Gestión 2000. ISBN: 9788480883078

Solano-Fleta, Luis (2001). "El papel profesional de las relaciones públicas en la administración de la controversia pública". Revista de comunicación de la SEECI, n. 8, pp. 14-29.

https://doi.org/10.15198/seeci.2001.8.14-29

Solano-Santos, Luis-Felipe (2009). "Relaciones públicas, responsabilidad social corporativa e imagen pública en la actual crisis". Vivat academia, revista de comunicación, n. 103, pp. 27-41.

https://doi.org/10.15178/va.2009.103.27-41 
Valdez-Zepeda, Andrés; Borrayo-Rodríguez, Carmen-Leticia; Muñoz-Guzmán, Miguel (2018). “Las relaciones públicas y la comunicación en los desastres naturales. El caso del sismo del 19 de septiembre de 2017 en México". Revista latina de comunicación social, n. 73, pp. 447-461.

https://doi.org/10.4185/RLCS-2018-1264

Van-Ruler, Betteke; Verčič, Dejan; Bütschi, Gerhard; Flodin, Bertil (2000). European body of knowledge on public relations / communication management. Report of the Delphi Research Project 2000. Ghent/Ljubljana: European Association for Public Relations Education and Research.

http://www.researchgate.net/publication/259672052_The_European_body_of_knowledge_on_public_relations_ communication_management_The_report_of_the_delphi_research_project_2000

Vázquez-Cano, Esteban; Fombona-Cadavieco, Javier; Bernal, César (2016). "Análisis computacional de las características ortotipográficas y paralingüísticas de los tweets periodísticos". El profesional de la información, v. 25, n. 4, pp. 588598.

https://doi.org/10.3145/epi.2016.jul.08

Verčič, Dejan (2000). "The European public relations body of knowledge”. Journal of communication management, n. 4, pp. 341-354.

https://doi.org/10.1108/eb023531

Villafañe-Gallego, Justo (coord.) (1999). El estado de la publicidad y el corporate en España y Latinoamérica. Madrid: Departamento de Comunicación Audiovisual y Publicidad I. Universidad Complutense.

Villafañe-Gallego, Justo (coord.) (2001). El estado de la publicidad y el corporate en España y Latinoamérica. Madrid: Pirámide. ISBN: 9788436815856

Villalba, Mamen (2019). "Relaciones Públicas”. Blog de Mamen Villalba.

http://www.mamenvillalba.com/mis-profesiones/las-relaciones-publicas

Viñas-Rexach, Francesc (2003). Joan Viñas Bona. El goig de viure. Barcelona: Editorial Edimutra. ISBN: 8486062918

Xifra-Triadú, Jordi (2006). "Pioneros e ignorados: la escuela de París y la doctrina europea de Relaciones Públicas". Ámbitos, n. 15, pp. 449-460.

https://colegiorrpp.cl/Jordi_Xifra_La_escuela_de_Paris_y_la_doctrina_europea_de_las_relaciones_publicas.pdf

Xifra-Triadú, Jordi (2008). “Modelos de las relaciones públicas políticas: Análisis de la situación en Cataluña". Revista latina de comunicación social, n. 63, pp. 392-399.

https://doi.org/10.4185/RLCS-63-2008-789-392-399

YouTube canal "El publicista" (s/f). Pedro Prat Gaballi, miembro de la Academia de Publicidad.

http://www.youtube.com/watch?v=ockWcXRsQTs

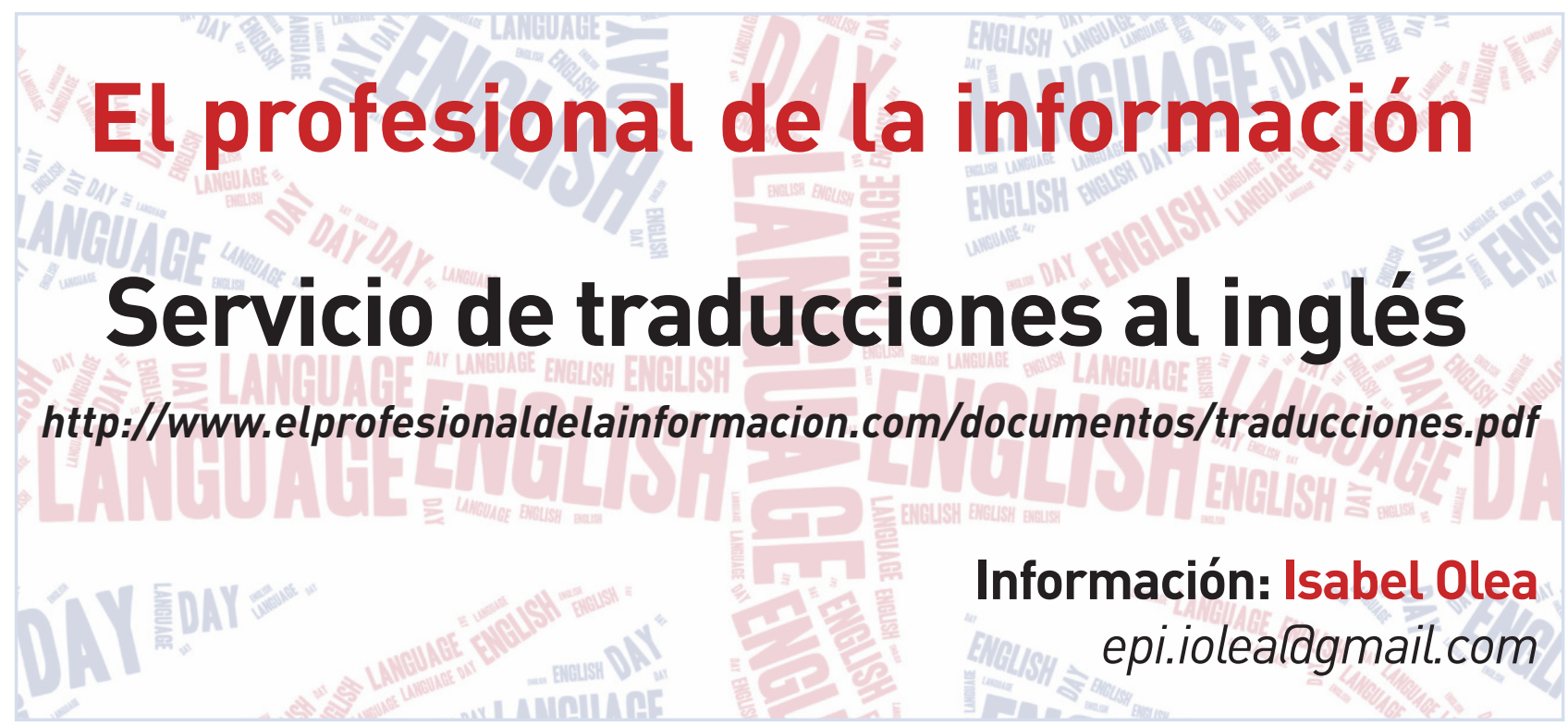

